\title{
¿Son los estados de excepción el problema? El ejercicio de la función legislativa a partir de la delegación expresa del Congreso: el caso colombiano***
}

\section{Are states of emergency the problem? The exercise of the legislative function from the express delegation of the Congress: The Colombian case}

\author{
RESUMEN
}

Una de las razones que justifica el rechazo a los Estados de excepción es el peligro que supone para una democracia que el ejecutivo asuma el ejercicio de la función legislativa. No obstante, un estudio detenido de los decretos con fuerza de ley que ha expedido el presidente de la República entre 1974 y 2014 pone en evidencia que esta función ha sido ejercida en una proporción sustancialmente mayor a partir de la delegación expresa que el propio Congreso ha hecho de ella. Contrario entonces a lo que afirman numerosos

Doctora en Derecho y magíster en Derecho Público por la Universidad Carlos III de Madrid (UC3M), España. Especialista en Derecho Constitucional y Parlamentario por la Universidad Externado de Colombia. Abogada de la Universidad Pontificia Bolivariana (Medellín). Docente de la Institución Universitaria de Envigado. Correo electrónico: anacatalina.arango@ derechoyjusticia.net ORCID: https://orcid.org/0000-0001-8895-0702.

Recibido el 21 de marzo del 2019, aprobado el 28 de enero del 2020.

Para citar el artículo: ARANGo Restrepo A. C. ¿Son los estados de excepción el problema? El ejercicio de la función legislativa a partir de la delegación expresa del Congreso: el caso colombiano. En Revista Derecho del Estado, Universidad Externado de Colombia. N. ${ }^{\circ} 46$, mayoagosto de 2020, pp. 189-222.

DOI: https://doi.org/10.18601/01229893.n46.08

*** Una versión preliminar de este trabajo hace parte de la tesis doctoral Mutaciones del presidencialismo. La transformación del poder presidencial en Colombia (1974-2010), defendida en la Universidad Carlos III de Madrid y financiada por el Departamento Administrativo de Ciencia, Tecnología e Innovación de la República de Colombia (COLCIENCIAs), a través del Programa de Formación Doctoral en el Exterior (Convocatoria 617 de 2013).

Agradezco a Andrea Greppi y Julián Gaviria Mira sus valiosos comentarios que han enriquecido la versión inicial de este artículo. 
estudios, no se trata de un Congreso que observa impotente cómo el ejecutivo utiliza los Estados de excepción para arrogarse la función legislativa sino de un Congreso que participa activamente en la transferencia de la misma y en el desequilibrio de poderes que de ella resulta. Este trabajo tiene por objeto advertir sobre la necesidad de incorporar a la discusión otras figuras, como la delegación de facultades extraordinarias, que pueden llegar a ser más invasivas de las funciones del parlamento que los Estados de excepción y que suponen replantear las medidas que se han adoptado en Colombia para revertir la concentración de poderes en cabeza del ejecutivo.

PALABRAS CLAVE

Presidencialismo, actuación unilateral, facultades extraordinarias, estados de excepción.

\section{ABSTRACT}

One of the reasons that justifies the rejection of states of emergency is the danger that supposes for a democracy that the executive assumes the exercise of the legislative function. However, a careful study of the decrees issued by the President between 1974 and 2014 shows that the executive has exercised the legislative function in a greater proportion based on the delegation that the Congress itself has made of it. Thus, contrary to what has been stated, it is not a congress that observes how the executive assumes its functions but a congress that actively participates in the transfer of them. This work aims to warn about the need to include in the discussion other figures that may be even more invasive of the functions of parliament than the states of emergency and to rethink the measures that the constitutional reforms have adopted to moderate the concentration of powers in the executive.

\section{KEYWORDS}

Presidentialism, unilateral action, extraordinary powers, states of emergency.

SUMARIO

Introducción. 1. El Ejercicio de la función legislativa bajo la Constitución de 1886: Primer Periodo (1974-1991); 2 . El ejercicio de la función legislativa a partir de la expedición de la Constitución de 1991: segundo periodo (19912014); Conclusión. Referencias 


\section{INTRODUCCIÓN}

La fuerza o debilidad que tiene un presidente en un sistema político concreto puede medirse atendiendo a su habilidad para "poner su propio sello en la ley", esto es, de conseguir la aprobación de su agenda ${ }^{1}$. Para adelantar su agenda política, las constituciones le otorgan al presidente dos estrategias, una basada en los estatutos y otra, en el uso de las prerrogativas presidenciales ${ }^{2}$. La primera, advierte Amorim, supone someterse al procedimiento legislativo ordinario y, por tanto, al recurrir a ella el presidente toma en consideración los puntos de vista e intereses de los legisladores. La segunda, por su parte, implica el uso tanto de las prerrogativas constitucionales (por ejemplo, los decretos) como de las prácticas políticas paraconstitucionales que le permiten actuar de forma unilateral. Para escoger su estrategia, el presidente hace una serie de cálculos que dependen de sus convicciones, de sus preferencias, de sus poderes partidistas, de los incentivos institucionales y de las condiciones económicas, entre otros factores ${ }^{3}$.

Respecto a la actuación unilateral, la facultad de expedir decretos con fuerza de ley ${ }^{4}$ le permite al presidente adoptar medidas que adquieren el mismo

1 Shugart, M. y Mainwaring, S. Presidentialism and Democracy in Latin America: Rethinking the Terms of the Debate. En Mainwaring y Shugart (eds.). Presidentialism and Democracy in Latin America. Cambridge: Cambridge University Press, 1997, p. 40.

2 Amorim Neto, O. The Presidential Calculus: Executive Policy Making and Cabinet Formation in the Americas. Comparative Political Studies, Vol. 39, n. ${ }^{\circ} 4,2006,416$.

3 Teniendo en cuenta que el presidente intenta siempre anticipar la reacción del congreso, la medida en que este recurre a sus facultades unilaterales ha sido explicada por algunos autores en la conformación política del parlamento. En efecto, advierten Cox y Morgenstern, el presidente anticipa si tiene una amplia mayoría en el congreso que acogerá cualquiera de sus propuestas o si carece de dicha mayoría y por tanto sus propuestas serán rechazadas. El cálculo de las respuestas del congreso le permite utilizar diferentes poderes institucionales y escoger una estrategia óptima para obtener la aprobación de sus iniciativas. Ver Cox, G. y Morgenstern, S. Latin America's Reactive Assemblies and Proactive Presidents. Comparative Politics, Vol. 33, n. . 2, 2001, 171. Mayer, por su parte, ha advertido que la expedición de decretos varía en función del ambiente político al que el presidente se enfrenta y que este utiliza más esta facultad cuando se acerca la terminación de su mandato y está buscando la reelección inmediata o cuando su sucesor hace parte del partido de la oposición. De igual forma, tenderá a hacer un mayor uso de sus poderes unilaterales a medida que su gestión obtiene bajos niveles de aprobación en la opinión pública. Ver MAYer, K. Executive Orders and Presidential Power. The Journal of Politics, Vol. 61 , n. ${ }^{\circ} 2,1999$.

4 Los decretos con fuerza de ley deben diferenciarse de aquellos que tienen por objeto reglamentar la ley. Como su nombre lo indica, el primer tipo de decretos tiene el mismo rango de la ley y, por tanto, puede derogar o suspender las existentes. Los decretos reglamentarios, en cambio, son aquellos que expide el ejecutivo con el fin de implementar las leyes existentes en el ejercicio de su función de ejecutar la ley. Estos decretos están subordinados a la ley y en esta medida, los tribunales administrativos pueden dejarlos sin efectos cuando consideren que exceden el ámbito de la ley que se proponen aplicar. Ver CARey, J. y Shugart, M. Calling Out the Tanks or Filling Out the Forms? En CARey y Shugart (ed.). Executive Decree Authority. Cambridge: Cambridge University Press, 1998, pp. 12-13. 
rango de la ley de forma inmediata y sin la intervención del Congreso ${ }^{5}$. Esta facultad es un típico poder proactivo que le da al presidente la posibilidad de cambiar el statu quo, al menos provisionalmente y aun cuando el Congreso no hubiera consentido en ello ${ }^{6}$. Si bien el parlamento conserva la facultad de oponerse a los decretos y derogarlos, a diferencia del proyecto legislativo, estos tienen efectos jurídicos inmediatos que le otorgan al presidente un margen para moverse antes de que el parlamento alcance a reaccionar. La facultad de expedir decretos constituye entonces una potente fuente de poder presidencial que le permite al ejecutivo moverse primero y de forma unilateral, dejando en manos de las demás instituciones, como el Congreso o los tribunales, la decisión de revertir sus medidas?

No debe sobreestimarse, sin embargo, la capacidad del Parlamento de oponerse a la acción unilateral del presidente. Los problemas que implica su actuación colectiva hacen que tenga enormes dificultades para responder a tiempo y de forma coherente, o incluso para dar cualquier tipo de respuesta al ejecutivo ${ }^{8}$. Además, si el Congreso aprueba una ley para revertir un decreto, al presidente le queda una última herramienta para oponerse: la facultad de vetar la ley ${ }^{9}$. Los tribunales por su parte, aunque pueden anular las decisiones del ejecutivo, deben esperar a que el asunto llegue a sus manos y una decisión definitiva puede llegar a tardar meses o incluso años ${ }^{10}$. En este sentido, el rechazo a la facultad del presidente de expedir decretos se sustenta

5 Ibid, p. 10.

6 Shugart, M. y Mainwaring, S. Presidentialism and Democracy in Latin America: Rethinking the Terms of the Debate. En Mainwaring y Shugart (edit.). Presidentialism and Democracy in Latin America. Cambridge: Cambridge University Press, 1997, pp. 44-45.

7 MaYer, K. With The Stroke of a Pen: Executive Orders and Presidential Power. Princeton, New Jersey: Princeton University Press, 2001, 24-29.

8 Moe, T. y Howell, W. The Presidential Power of Unilateral Action. The Journal of Law, Economics, and Organization, Vol. 15, n. . 1, 1999, 140.

9 Pero incluso cuando un presidente impulsa su agenda pasando por encima del congreso, debe conseguir un apoyo suficiente en él como para evitar que revierta las medidas adoptadas por decreto. De esta forma, señalan Carey y Shugart, la facultad que se le otorga a un presidente de expedir decretos no tiene grandes repercusiones sobre la política legislativa si no va acompañada de un poder de veto que le permita oponerse a los intentos del congreso de revertir sus medidas. Este poder proactivo aislado solo adquiere relevancia si el presidente, careciendo de poderes reactivos como el de veto, se enfrenta a un congreso lo suficientemente dividido como para que no consiga una mayoría que le permita derogar sus decretos mediante la expedición de una nueva ley. Ver Carey, J. y Shugart, M. Calling Out the Tanks or Filling Out the Forms? En Carey y Shugart (ed.). Executive Decree Authority. Cambridge: Cambridge University Press, 1998, p. 8.

10 Ver Mayer, K. With The Stroke of a Pen: Executive Orders and Presidential Power. Princeton, New Jersey: Princeton University Press, 2001. Según Howell la medida en que un presidente recurre a los decretos va a depender de las posibilidades que tiene el congreso de derogarlos a través de la legislación y del control que efectivamente ejercen los tribunales sobre ellos. Ver Howell, W. Unilateral Powers: A Brief Overview. Presidential Studies Quarterly, Vol. 35, n. $^{\circ} 3,2005$. 
principalmente en la idea de que estos son un ejemplo de poder sin control y una forma de evadir la opinión pública y las restricciones constitucionales ${ }^{11}$.

Pero esto no quiere decir que el presidente pueda actuar de forma temeraria en la ampliación de su poder. De hecho, advierten Moe y Howell ${ }^{12}$, si va demasiado lejos o demasiado rápido o si toca temas sensibles en el momento equivocado, tendrá que asumir un costo político que se traduce o bien en la reversión de sus medidas por parte del Congreso o de las cortes, o peor aún, en la creación de una oposición que puede desafiar otros aspectos de su agenda política. Esto supone entonces que el presidente tiene que calcular ex ante los costos y los beneficios que conlleva la ampliación de su poder y que incluso en su actuación unilateral está constreñido a actuar de forma estratégica y con moderación ${ }^{13}$. En este sentido, afirman Shugart y Haggard, los decretos son más exitosos para cambiar una política cuando el presidente los usa con miras a impulsar una política compartida con el Parlamento - porque este le ha delegado expresamente tal facultad o de manera implícita le ha dado vía libre para ello - o sin ser compartida con él, este no se opone a ella al punto de desencadenar una respuesta en contra suya o rápidamente la política consigue adecuarse a los intereses del legislativo. Por el contrario, un fuerte desacuerdo sobre el cambio impulsado por el presidente, puede dar lugar a un conflicto entre las ramas con consecuencias adversas no solo sobre la política concreta sino incluso para la estabilidad del gobierno ${ }^{14}$.

Ahora bien, la Constitución colombiana autoriza al presidente a actuar de forma unilateral en dos supuestos. Primero, durante los estados de excepción contemplados en los artículos 212 a $215 \mathrm{y}$, segundo, a partir de las facultades extraordinarias que le otorga el Congreso para que ejerza la función legislativa por un tiempo determinado y sobre materias específicas (artículo 150 numeral 10). En el primer caso se trata de una delegación que hace la Constitución al presidente ${ }^{15}$, mientras que, en el segundo, de la delegación que hace el Congreso a un presidente concreto. De esta forma, el primer fenómeno es

11 MAYER, K. With The Stroke of a Pen: Executive Orders and Presidential Power. Princeton, New Jersey: Princeton University Press, 2001, p. 9.

12 Moe, T. y Howell, W. The Presidential Power of Unilateral Action. The Journal of Law, Economics, and Organization, Vol. 15, n. ${ }^{\circ} 1,1999,138$.

13 Ibíd.,p. 141.

14 Shugart, M. y Haggard, S. (2001). Institutions and Public Policy in Presidential Systems. En Haggard, S. (ed.) Presidents, Parliaments, and Policy. Cambridge: Cambridge University Press, 2001, pp. 99-100.

15 No todas las constituciones reconocen poderes de emergencia al ejecutivo. En algunas democracias para hacer frente a situaciones de emergencia es el congreso quien, a través de leyes ordinarias, delega en el ejecutivo poderes especiales y temporales. En estos casos, es el congreso quien tiene la facultad tanto de reconocer una emergencia como de crear los poderes para lidiar con ella. Las ventajas y riesgos de uno y otro modelo pueden consultarse en FEREJOHN, J. y PAsquino, P. The Law of the Exception: A Typology of Emergency Powers. International Journal of Constitutional Law, Vol. 2, n. ${ }^{\circ} 2,2004$. 
constitucional y hace parte del diseño institucional, mientras que el segundo es condicional y hace parte del proceso político ${ }^{16}$.

La delegación que hace la Constitución le otorga grandes ventajas al presidente. Primero, advierte Negretto, lo instituye como "el único actor facultado para declarar la existencia de una emergencia", de tal forma que le asigna un amplio margen de discrecionalidad para interpretar qué hechos constituyen una emergencia y, segundo, le permite modificar inmediatamente el statu quo sin que el Congreso tenga la oportunidad de discutir y evaluar las consecuencias de este cambio legislativo. De esta forma, la decisión que puede tomar el parlamento una vez se ha expedido el decreto ya no supone elegir entre el statu quо y las medidas adoptadas por el presidente, sino entre la nueva legislación y el resultado que se seguiría si enmienda o deroga el decreto una vez este ha surtido efectos ${ }^{17}$. No obstante, es la delegación que hace directamente el Congreso la que le otorga mayores poderes al presidente para actuar de forma unilateral pues, si bien puede pensarse que los efectos de esta actuación son inocuos porque el presidente se sujeta a los límites trazados por el Congreso, lo cierto es que la facultad de legislar corresponde a este y su delegación supone en sí misma una ampliación de las facultades del ejecutivo que inclina la balanza de poderes en su favor ${ }^{18}$.

En el estudio de los regímenes políticos latinoamericanos se ha vuelto un lugar común afirmar que el uso continuado que hace un presidente de su facultad de expedir decretos ley es prueba de que el Parlamento está siendo marginado y las instituciones democráticas son ineficientes ${ }^{19}$. Hasta el estudio de Carey y Shugart pocos autores habían considerado la posibilidad de que estos decretos pudieran significar algo diferente a una clara usurpación

16 Pereira, C., Power, T. y Rennó, L. Under What Conditions Do Presidents Resort to Decree Power? Theory and Evidence from the Brazilian Case. The Journal of Politics, Vol. 67, n. ${ }^{\circ} 1,2005,195-196$.

17 Negretto, G. ¿Gobierna solo el Presidente? Poderes de decreto y diseño institucional en Brasil y Argentina. Desarrollo Económico, Vol. 42, n. ${ }^{\circ}$ 167, 2002, 381-382.

18 Moe, T. y Howell, W. The Presidential Power of Unilateral Action. The Journal of Law, Economics, and Organization, Vol. 15, n. ${ }^{\circ} 1,1999,142$.

19 También para el caso norteamericano existen numerosos estudios que llaman la atención sobre el abuso que ha hecho el presidente de esta facultad. Ver CAREY, J. y Shugart, M. Calling Out the Tanks or Filling Out the Forms? En CAREY y Shugart (ed.). Executive Decree Authority. Cambridge: Cambridge University Press, 1998, 1-32; Deering, C. y Maltzman, F. The Politics of Executive Orders: Legislative Constraints on Presidential Power. Political Research Quarterly, Vol. 52, n- ${ }^{\circ} 4$, 1999, 767-783; Moe, T. y Howell, W. The Presidential Power of Unilateral Action. The Journal of Law, Economics, and Organization, Vol. 15, n. ${ }^{\circ}$ 1, 1999, 132-179; MAYER, K. With The Stroke of a Pen: Executive Orders and Presidential Power. Princeton, New Jersey: Princeton University Press, 2001; Shugart, M. y HagGard, S. Institutions and Public Policy in Presidential Systems. En Haggard (edit.) Presidents, Parliaments, and Policy. Cambridge: Cambridge University Press, 2001, pp. 64-102; Cox, G. y Morgenstern, S. Latin America's Reactive Assemblies and Proactive Presidents. Comparative Politics, Vol. 33, n. . 2, 2001, 171189 , entre otros. 
de las funciones legislativas ${ }^{20}$. En su investigación ponen en evidencia que en repetidas ocasiones esta facultad es ejercida sin que ello suponga pasar por encima del parlamento, es decir, en situaciones de normalidad en las que está sesionando y bajo los parámetros que este ha establecido con plena observancia de la Constitución y la ley ${ }^{21}$. En efecto, la asamblea puede preferir que la política sea hecha por el ejecutivo a través de decretos y no mediante el procedimiento legislativo ordinario cuando las negociaciones a las que se enfrenta en el proceso de creación de la ley se dificultan o cuando sus intereses convergen porque el presidente cuenta con una mayoría que lo respalda. También cuando cree que el presidente tiene mejores recursos técnicos para tomar las medidas y puede hacerlo de forma expedita o existe un poder judicial independiente con autoridad para pronunciarse sobre la constitucionalidad de los decretos expedidos por el ejecutivo y sobre la extralimitación o no de sus funciones ${ }^{22}$.

El caso colombiano apunta precisamente en esta dirección. Un estudio detenido de la actuación del ejecutivo pone en evidencia que este se ha arrogado la función legislativa principalmente a partir de la delegación expresa que el propio Congreso ha hecho de la misma. Es curioso, sin embargo, que la mayoría de estudios en Colombia resalten la sustitución del parlamento y el reforzamiento del presidencialismo a partir de la declaratoria permanente de un estado de excepción ${ }^{23}$. Esto no quiere decir que esta figura no sea pro-

20 Carey, J. y Shugart, M. Calling Out the Tanks or Filling Out the Forms? En CARey y Shugart (ed.). Executive Decree Authority. Cambridge: Cambridge University Press, 1998, pp. 3-4.

21 Sobre este punto, advierte Negretto, si bien en Latinoamérica la facultad de expedir decretos se utilizó como un "instrumento de gobierno regular", su inclusión en la Constitución no debe buscarse simplemente en "los legados institucionales de un pasado autoritario" pues, más allá de la influencia que haya tenido el presidente de turno sobre el proceso constituyente, esta responde a una inquietud compartida por diferentes actores políticos de moderar el principio de separación de poderes en situaciones de extrema gravedad y urgencia para que puedan introducirse cambios rápidos en la legislación que permitan hacer frente a situaciones de crisis. Ver NeGRetTo, G. (2001). El constitucionalismo puesto a prueba: decretos legislativos y emergencia económica en América Latina. Isonomía, n. ${ }^{\circ}$ 14, 2001, 80.

22 Carey, J. y Shugart, M. 1998. Calling Out the Tanks or Filling Out the Forms? En CAREY y Shugart (ed.). Executive Decree Authority. Cambridge: Cambridge University Press, 1998, pp. 17-18.

23 Ver: Gallón Giraldo, G. Quince años de estado de sitio en Colombia, 1958-1978. Bogotá: Editorial América Latina, 1979; García VIllegas, M. Constitucionalismo perverso. Normalidad y anormalidad constitucional en Colombia (1957-1997). En SANTos y García Villegas (dirs.). El caleidoscopio de las justicias en Colombia. Bogotá: Uniandes-Siglo del Hombre-Colciencias-ces, Tomo I, 2001; García Villegas, M. y Uprimny, R. “¿Controlando la excepcionalidad permanente en Colombia? Una defensa prudente del control judicial de los estados de excepción", 2005; Ariza, L. y Barreto A. "La Corte Constitucional frente a la excepcionalidad: diez años de control material laxo y discursivo". En Derecho Constitucional. Perspectivas críticas. Bogotá: Observatorio de Justicia Constitucional-Universidad de los Andes, 2001, 137-171; BARRETO, A. "La generación del estado de sitio: el juicio a la anormalidad institucional colombiana en la Asamblea Nacional Constituyente de 1991". Precedente. Revista 
blemática ni que su uso no haya dado pie a graves violaciones de los derechos humanos en el país. El problema de la lectura que los académicos han hecho hasta ahora es que supone la anulación de un Congreso que observa impotente el arrebato de sus funciones cuando en realidad este ha desempeñado un papel activo en la transferencia de las mismas y en el desequilibrio de poderes que de ella resulta.

Este trabajo tiene entonces por objeto llamar la atención sobre el hecho de que cuando el presidente recurre a los mecanismos "excepcionales" en lugar de los "ordinarios" para conseguir la aprobación de su agenda, ha preferido, en una proporción sustancialmente mayor, solicitar al Congreso la delegación de la función legislativa que ejercerla con las facultades que le otorgan los Estados de excepción.

Con el fin de corroborar esta afirmación e identificar en qué medida la actuación unilateral del ejecutivo se ha llevado a cabo a través de una u otra figura, se estudian los decretos con fuerza de ley que ha expedido el presidente en los años comprendidos entre 1974 y $2014^{[24]}$. Estos cuarenta años se dividieron en dos segmentos atendiendo a la expedición de la Constitución de 1991 (6 de julio). La elección de esta reforma constitucional como el hecho que fracciona el periodo se explica en las profundas transformaciones que esta supuso sobre el ejercicio del poder presidencial y, en especial, de las facultades legislativas del presidente. Conviene advertir que este trabajo aborda al poder ejecutivo como institución de forma que el objeto de estudio no son los presidentes puntuales que componen el periodo. No obstante, teniendo en cuenta que existen variaciones en la forma en que se ejerce la facultad de expedir decretos con fuerza de ley dentro un mismo segmento y que, por tanto, no pueden ser explicadas a partir de cambios normativos, se hace referencia a algunas particularidades que pueden atribuirse a un presidente concreto y que son útiles en la medida en que permitirían, en futuras investigaciones, establecer relaciones entre la actuación unilateral del ejecutivo y las circunstancias políticas a las que este se enfrenta.

En la recopilación de los datos, se toman las leyes que son sancionadas por cada presidente durante su mandato y se clasifican de tal forma que puedan distinguirse las leyes en las que el Congreso delega su función legislativa (leyes de facultades extraordinarias) de aquellas en que directamente la ejerce. De igual forma, las leyes se agrupan en cuatro materias que facilitan la tarea de identificar, a grandes rasgos, la trascendencia de los asuntos de

Jurídica, Vol. 1, 9-48 y VANEGAS GiL, P. La Constitución colombiana y los estados de excepción: veinte años después. Revista Derecho del Estado, n. ${ }^{\circ} 27,2011,261-290$, entre otros.

24 Para el estudio de la actividad de las ramas ejecutiva y legislativa se han utilizado los datos recopilados en el "Buscador legislativo" de la página web de la Cámara de Representantes del Congreso de la República de Colombia. Así mismo, se utilizó la clasificación en él propuesta para agrupar las leyes y decretos expedidos desde 1968. 
los cuales se ocupa el Parlamento. Respecto de los decretos expedidos por el presidente, se recopilan solo aquellos que suponen un claro ejercicio de la función legislativa y que, por tanto, son equiparables en sus efectos a la ley, estos son, los decretos ley o extraordinarios y los decretos legislativos ${ }^{25}$. Los actos de cada rama se filtran por año con el fin de que sea posible establecer conexiones, en futuras investigaciones, entre el fortalecimiento del presidencialismo y las circunstancias políticas por las que atraviesa el país en un momento determinado. Así mismo, se ordenaron teniendo en cuenta el inicio y fin de cada mandato presidencial de forma que el primer año empieza siempre con la posesión del presidente el 7 de agosto y el último, termina con el fin de su periodo el 6 de agosto. Para las leyes se utilizó como criterio la fecha de sanción presidencial sin tomar en cuenta que esta resultara de un proyecto de iniciativa de otro gobierno.

Por último, es importante advertir que la reunión de estos datos no tiene la pretensión de llevar a cabo un trabajo empírico. Su recolección se justifica en esta investigación solo como una herramienta orientativa sobre la que se apoya la hipótesis de que no se ha prestado suficiente atención a la delegación que ha hecho el Congreso de su función legislativa a pesar de ser esta la principal herramienta que utiliza el presidente para actuar de forma unilateral.

\section{EL EJERCICIO DE LA FUNCIÓN LEGISLATIVA BAJO LA CONSTITUCIÓN DE 1886: PRIMER PERIODO (1974-1991) ${ }^{26}$}

Los poderes legislativos que se arroga el presidente entre 1974 y 1991 son de tal magnitud que algunos afirmaron que era "el primer legislador del país" ${ }^{27}$. De hecho, si se toman los actos del ejecutivo que suponen un claro ejercicio de la función legislativa y que, por tanto, son equiparables en sus efectos a la ley - esto es, los decretos extraordinarios y los decretos legislativos - se encuentra que el ejecutivo no solo hace uso de esta función, sino que incluso sobrepasa la ejercida por el Congreso en un $16.9 \%$ pues, mientras el presi-

25 Los decretos extraordinarios son los expedidos en virtud de una delegación expresa que hace el congreso al presidente (a partir de una ley de facultades extraordinarias) para que ejerza la función legislativa sobre materias específicas y por un tiempo determinado (artículo 150 No. 10 CP). Los decretos legislativos, en cambio, comprenden tanto los que declaran el estado de excepción como aquellos que adoptan las medidas tendientes a conjurar la perturbación (artículos 214-215 CP). De la categoría de decretos con fuerza de ley se excluyen aquellos decretos de contenido administrativo como los decretos reglamentarios; los que promulgan tratados, convenios u otros actos internacionales y los que ordenan la publicación de actos legislativos.

26 El periodo empieza el 7 de agosto de 1974 (fecha en que se posesiona el presidente Alfonso López Michelsen) y termina el 6 de julio de 1991 (fecha en que se promulga la Constitución de 1991).

27 ARCHER, R. y CHERNICK, M. El presidente frente a las instituciones nacionales. En VÁsQUEZ URRUTIA (ed.). La democracia en blanco y negro: Colombia en los años ochenta. Bogotá: Uniandes, 1989, p. 36. 
dente expide 1.455 decretos con fuerza de ley, el Congreso aprueba 1.209 leyes (ver gráfico 1). De las leyes aprobadas, 86 revistieron al presidente de facultades extraordinarias para legislar y a partir de ellas, el ejecutivo expidió 1.106 decretos extraordinarios. Esto quiere decir que de los decretos con fuerza de ley, el $76 \%$ es expedido a partir de una delegación expresa que hace previamente el Congreso de sus facultades y apenas un $24 \%$ resulta de la declaratoria de un estado de excepción (ver gráfico 2).

Estos datos por si solos no arrojan un resultado inmediato sobre el impacto que tuvo la expedición de uno u otro tipo de decretos en la sustitución de la función legislativa. El peso de cada categoría debe medirse además atendiendo a las materias sobre las cuales versan. Pero incluso un análisis cualitativo de la actividad del Congreso arroja resultados más contundentes. Si se clasifican las leyes sancionadas de tal forma que se pueda determinar, a grandes rasgos, la importancia de los asuntos sobre los que decidió, se encuentra que su pérdida de influencia es sin duda preocupante. Esta clasificación puede hacerse atendiendo a las materias que con mayor frecuencia son abordadas por la legislación. Podrían agruparse así en leyes que: 1) otorgan facultades extraordinarias al presidente; 2) aprueban tratados, convenios u otros actos internacionales; 3) aprueban o modifican el Presupuesto Anual General de la Nación; 4) rinden homenajes, honores u ordenan la creación o conservación de monumentos y 5) no encajan en ninguna de las categorías anteriores. En la última categoría, que corresponde apenas a un 39\% del total de las leyes sancionadas en este periodo, quedan incluidas las leyes que se refieren a la reforma de los códigos civil, penal, de procedimiento penal, laboral, comercial y contencioso administrativo; la regulación de asuntos fiscales, financieros y bancarios; la creación o transformación de superintendencias; el reconocimiento y regulación del ejercicio de las profesiones; la aprobación de autorizaciones al gobierno; la concesión de amnistías, en fin, todos aquellos asuntos que por su importancia en una democracia, deben ser ampliamente debatidos y decididos por el Parlamento.

Por su parte, los asuntos del ejecutivo pueden clasificarse en: 1) decretos ley o extraordinarios (que se expiden a partir de una ley de facultades extraordinarias y que versan sobre las mismas materias que las leyes expedidas por el Congreso y clasificadas en el numeral quinto); 2) decretos legislativos que declaran un estado de excepción; 3) decretos legislativos expedidos en virtud de un estado de excepción y destinados "exclusivamente" a conjurar la crisis e impedir la extensión de sus efectos y 4) decretos autónomos ${ }^{28}$.

28 Los decretos autónomos son un tipo de decretos de contenido legislativo expedidos por el presidente en ejercicio de facultades directas que la Constitución le atribuye (numeral 14 del artículo 120 de la Constitución de 1886) y que bajo la Constitución de 1991 expide por delegación expresa de los numerales 11,15 y 16 del artículo 189 o de sus artículos transitorios. 


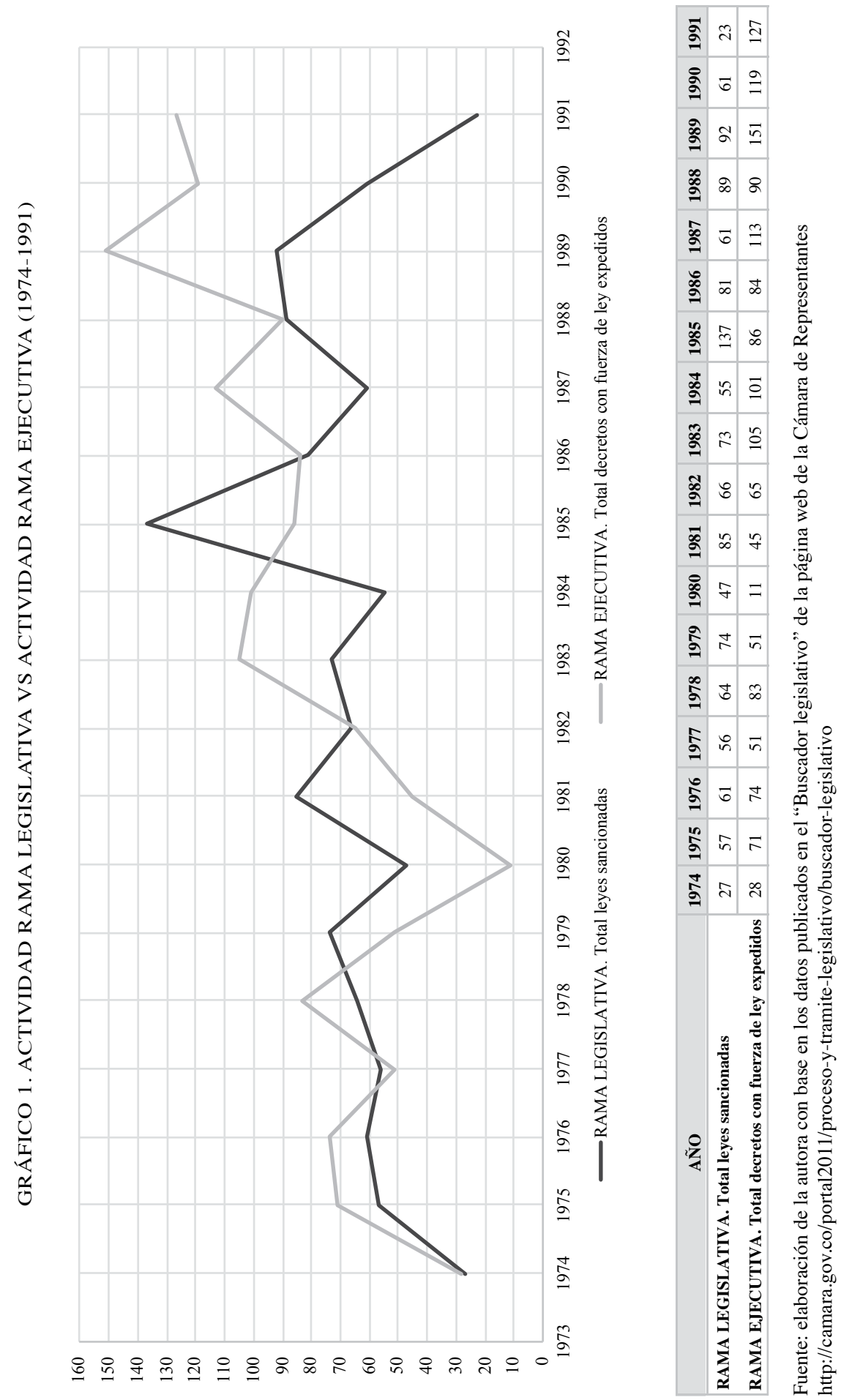


Ahora, si se comparan las leyes y los decretos que versan sobre aquellas materias que son de mayor importancia, esto es, si se compara la categoría 5 de las leyes con la categoría 1 de decretos, se encuentra que la distancia en el ejercicio de la función legislativa es aún mayor pues, sobre estas materias el Congreso aprueba apenas 472 leyes mientras el presidente expide 1.106 decretos (ver anexo, tabla 1). La función legislativa ejercida por el Congreso corresponde entonces apenas a un $42.67 \%$ de la llevada a cabo por el ejecutivo. Pero la gravedad del asunto no reside solo en el hecho de que el Parlamento ejerciera menos la función legislativa sino en que además delegó en el ejecutivo la regulación de las materias de mayor importancia. El presidente recibió facultades extraordinarias para expedir códigos como el Código de Policía Nacional (Decreto 1355 de 1970), el Código de Procedimiento Civil (Decreto 1400 de 1970), el Código de Comercio (Decreto 410 de 1971), el Código Penal (Decreto 100 de 1980), el Código Contencioso Administrativo (Decreto 01 de 1984), el Código de Régimen Departamental (Decreto 1222 de 1986), el Código de Régimen Municipal (Decreto 1333 de 1986), el Código Electoral (Decreto 2241 de 1986) y el Código del Menor (Decreto 2737 de 1989), entre otros. Es claro pues, que el presidente no solo ha absorbido en este periodo una gran parte de la función legislativa, sino que además, lo ha hecho en "tiempos de paz", es decir, a partir de una delegación expresa del Congreso y sin que medie la justificación de una "perturbación del orden público o económico".

Respecto a los decretos expedidos en virtud de un estado de excepción, se tiene que entre 1974 y 1991 es el gobierno de Julio César Turbay el que menos decretos legislativos expide. Así mismo, de los cinco presidentes de este periodo, Virgilio Barco y César Gaviria ${ }^{29}$ son los únicos que no recurren a la declaratoria de un estado de excepción. No obstante, los números estudiados de forma aislada pueden inducir a error. En efecto, en el caso de Virgilio Barco no hay ninguna declaratoria de un estado de excepción porque el presidente se posesiona bajo el estado de sitio que había decretado Belisario Betancur en 1984 y ello le permite gobernar la totalidad de su mandato haciendo uso de esta figura. También César Gaviria ejerce su mandato bajo la vigencia del mismo estado de sitio, que no levantará hasta la expedición de la Constitución de 1991. Por su parte, Julio César Turbay, que solo declara un estado de excepción al final de su mandato, también había heredado de Alfonso López Michelsen un estado de sitio que conserva hasta que le resta un mes a su mandato. En cuanto al bajísimo número de decretos que expide Julio César

29 Cuando se afirma que César Gaviria no recurrió a la declaratoria de ningún estado de excepción debe tenerse en cuenta que su mandato queda dividido en esta investigación por la expedición de la Constitución de 1991. En este sentido, Gaviria no declara ningún estado de excepción en la porción de su mandato que la antecede. Como se verá más adelante, luego de su expedición, recurre a ellos en cinco oportunidades. 
Turbay en comparación con los demás presidentes, la expedición de uno solo de ellos, el "Estatuto de seguridad" 30 , bastó para convertir a su gobierno en uno de los más represivos de los que se tenga registro desde la instauración del Frente Nacional. Este estatuto, recordado por su especial crudeza, dio vía libre al gobierno y a los militares en la persecución de toda forma de oposición. En este sentido, advierte Hartlyn, este instrumento represivo con el cual el gobierno se proponía debilitar la insurgencia guerrillera y atacar el narcotráfico, fue utilizado para combatir formas de criminalidad ordinaria pero sobre todo, como una herramienta de persecución política de aquellos que manifestaban su inconformidad con el gobierno. Sus medidas fueron especialmente contundentes con el sindicalismo, los estudiantes y todo tipo de activistas ${ }^{31}$. Respecto a Alfonso López Michelsen y Belisario Betancur, si bien son los presidentes que más recurren a los Estados de excepción (en cinco ocasiones cada uno), también son los únicos que gobernaron, así sea durante periodos muy breves, sin hacer uso de ellos.

La excesiva facilidad con la que el ejecutivo pudo recurrir a los estados de emergencia le permitió legislar sobre asuntos que no siempre guardaban conexión con la perturbación que justificaba su declaratoria. De hecho, los estados de excepción se desnaturalizan al punto de que, una situación que en principio es excepcional, termina por normalizarse. Entre 1970 y 1991, señalan García y Uprimny, Colombia vivió un $82 \%$ del tiempo bajo un estado de excepción ${ }^{32}$. En esta deformación, afirma García, intervienen dos instituciones: el Congreso y el gobierno. El primero, a través de la estrategia legislativa del "blanqueo" 33 que consiste en "convertir la normatividad de excepción en legislación ordinaria por medio de una ley del Congreso". El segundo, mediante una estrategia gubernamental de "transfiguración" que supone "prolongar la excepción indefinidamente en el tiempo, de tal manera que ya no dependa de las circunstancias que motivó su declaratoria" 34 .

30 Decreto 1923 de 1978.

31 Hartlyn, J. Presidentialism and Colombian Politics. En Linz y V alenzuela (edit.) The Failure of Presidential Democracy: The Case of Latin America, Vol. 2, Baltimore: The Johns Hopkins University Press, 1994, 233.

32 García Villegas, M. y Uprimny, R. ¿Controlando la excepcionalidad permanente en Colombia? Una defensa prudente del control judicial de los estados de excepción, 2005, p. 7.

33 Un caso emblemático es la incorporación en el Código Penal de algunas medidas adoptadas en el Estatuto de seguridad de Julio César Turbay como, por ejemplo, la extensión de la competencia de la jurisdicción militar para juzgar la comisión de determinados delitos por parte de civiles. Ver ARCHER, R. y ChERNICK, M. El presidente frente a las instituciones nacionales. En Vásquez Urrutia (ed.). La democracia en blanco y negro: Colombia en los años ochenta. Bogotá: Uniandes, 1989, p. 42.

34 García Villegas, M. Constitucionalismo perverso. Normalidad y anormalidad constitucional en Colombia (1957-1997). En SANTOS y GARCía VILLEGAS (dirs.). El caleidoscopio de las justicias en Colombia. Bogotá: Uniandes-Siglo del Hombre-Colciencias-CES, Tomo I, 2001, 333. 
En el desequilibrio del sistema no solo intervienen las ramas ejecutiva y legislativa. Los fallos de la Corte Suprema de Justicia, tímidos en su mayoría desde su creación en 1910, son decisivos en la expansión progresiva de los poderes del ejecutivo durante la mayor parte del siglo $\mathrm{xx}^{35}$. Sus fallos legitimaron la utilización desmedida del estado de sitio declarando la constitucionalidad de sus decretos y limitándose a revisar la legalidad del procedimiento, en lugar de su contenido ${ }^{36}$. En otros casos, la Corte directamente renunció a su función de ejercer el control sobre las actuaciones del Congreso y del ejecutivo a través del mecanismo de la inhibición ${ }^{37}$. Esta ausencia de control no solo tuvo graves repercusiones sobre la protección de los derechos y libertades ciudadanas, también dio lugar a una desfiguración del principio de separación de poderes en la que una parte importante de la función legislativa fue absorbida por el ejecutivo y la competencia de los jueces para juzgar un número creciente de delitos fue trasladada a la jurisdicción castrense.

En cuanto a los decretos ley o extraordinarios, de las 211 leyes sancionadas por el Congreso que acompaña a Alfonso López Michelsen, 15 revisten al presidente de facultades extraordinarias y dan lugar a la expedición de 219 de estos decretos. Esto quiere decir que el $74.48 \%$ de la función legislativa ejercida por el ejecutivo durante este mandato no es arrebatada haciendo uso de la figura de los estados de excepción sino delegada expresamente por el Parlamento. Si a esto se suma un análisis cualitativo que solo tenga en cuenta la importancia de los asuntos sobre los que decide el Congreso, se puede afirmar que su actividad fue todavía muchísimo inferior pues, las "leyes importantes" que aprueba representan apenas un $38.38 \%$ del total de su actividad. No obstante, fue Virgilio Barco el presidente que más recibió del Congreso facultades extraordinarias para legislar. A partir de 27 delega-

35 Un estudio de la jurisprudencia de la Corte Suprema de Justicia respecto a las facultades del ejecutivo durante los estados de sitio y su tendencia a inclinar la balanza a favor del ejecutivo, a quien entendía como "el guardián supremo del orden público", puede consultarse en: BARRETO, A. "La generación del estado de sitio: el juicio a la anormalidad institucional colombiana en la Asamblea Nacional Constituyente de 1991". Precedente. Revista Jurídica, Vol. 1, 15-26. En este trabajo el autor hace una reconstrucción de la creación, por parte de la Corte Suprema, de la "doctrina de las facultades implícitas", según la cual, la Constitución habría dotado al presidente implícitamente de todas aquellas facultades que fueran necesarias para que este pudiera cumplir con su deber de conservar y restaurar el orden público. Con la creación de esta doctrina, la Corte Suprema avaló los excesos del ejecutivo en el ejercicio de las facultades extraordinarias que le otorgaba el estado de sitio y justificó las graves restricciones a las libertades ciudadanas.

36 En este sentido, afirma Uprimny, aunque en ciertos casos el control de constitucionalidad ha puesto freno a la arbitrariedad del ejecutivo, en otros ha legitimado su autoritarismo declarando constitucional su actuación valiéndose de una interpretación laxa de las facultades del presidente. Ver UpRImNY YePes, R. "Estado de sitio y tratados internacionales en Colombia: una crítica a la jurisprudencia constitucional de la Corte". En GaLlón GiRALDo (comp.) Guerra y Constituyente. Bogotá: Comisión Andina de Juristas Seccional Colombiana, 1991, 91.

37 YePes ArCila, H. La reforma constitucional de 1968 y el régimen político colombiano. Manizales: Imprenta Departamental de Caldas, 1974, p. 346. 
ciones, Barco expide 349 decretos mientras que el Congreso aprueba - sobre las mismas materias de las que se ocupan estos decretos - 129 leyes. Según esto, la actividad legislativa del parlamento representa apenas un $36.96 \%$ de la ejercida por el ejecutivo. Por su parte, el gobierno de Belisario Betancur, es el segundo en expedir el mayor número de decretos con fuerza de ley en virtud de leyes de facultades extraordinarias. Con la firma de 265 decretos extraordinarios casi que duplica las leyes aprobadas por el Congreso que versan sobre las mismas materias. Gaviria expide, en apenas dos de los cuatro años que componen su mandato, 122 decretos extraordinarios a partir de 11 leyes que le otorgan facultades extraordinarias. Proporcionalmente, de nuevo es Turbay el que menos uso hace de estas facultades pese a recibir casi tantas delegaciones como los demás presidentes de este periodo. El número de decretos extraordinarios expedidos, que tampoco representa una cifra nada despreciable, equivale casi al doble de las leyes aprobadas por el parlamento (gráfico 2).

En estos diecisiete años se evidencia entonces una voluntad constante del Congreso de delegar su función legislativa en el presidente, de forma que su actuación unilateral se llevó a cabo, en su mayor parte, en situaciones de normalidad y con el beneplácito suyo y no, como hasta ahora se ha creído, a partir de la declaratoria de un estado de excepción. Si bien el uso que hizo el ejecutivo de los estados de sitio dio pie a un sinnúmero de excesos y violaciones a los derechos humanos - del que dejaron constancia la ciudadanía, distintas organizaciones internacionales e incluso funcionarios del propio Estado como congresistas, magistrados de la Corte Suprema y militares retirados - conviene llamar la atención sobre el hecho de que el presidente no consiguió la aprobación de la mayor parte de su agenda pasando por encima del Congreso. Esta delegación, sin embargo, señala Restrepo Piedrahita, no fue prevista por la Constitución de 1886. Es resultado de una interpretación extensiva que hizo el Parlamento de las facultades extraordinarias y de la convalidación que recibió por parte de la Corte Suprema de Justicia esta interpretación. En efecto, advierte el autor, la Constitución no contempló dos clases diferentes de facultades extraordinarias, unas para el estado de sitio y otras para tiempos de paz, sino una única modalidad que el presidente ejercería bajo el estado de sitio - decretado por conmoción interior o guerra exterior - y destinada a prevenir o reprimir perturbaciones del orden público ${ }^{38}$.

38 Restrepo Piedrahita, C. Las facultades extraordinarias. Bogotá: Publicaciones Universidad Externado de Colombia, 1973, p. 39. No obstante, continúa el autor, el carácter excepcional que tenían estas facultades empieza a desvirtuarse cuando el congreso, mediante la expedición de la llamada "ley de los caballos" (ley 61 de 1888), autoriza al presidente a ejercer facultades extraordinarias por fuera del estado de sitio, es decir, en tiempos de paz y por tanto, en situaciones que no implicaban perturbación del orden público. Aunque el congreso tenía la costumbre de delegar al ejecutivo la función legislativa sobre materias que eran competencia del propio congreso, lo hacía siempre recurriendo a las leyes de "autorizaciones" (artículo 76, nume- 

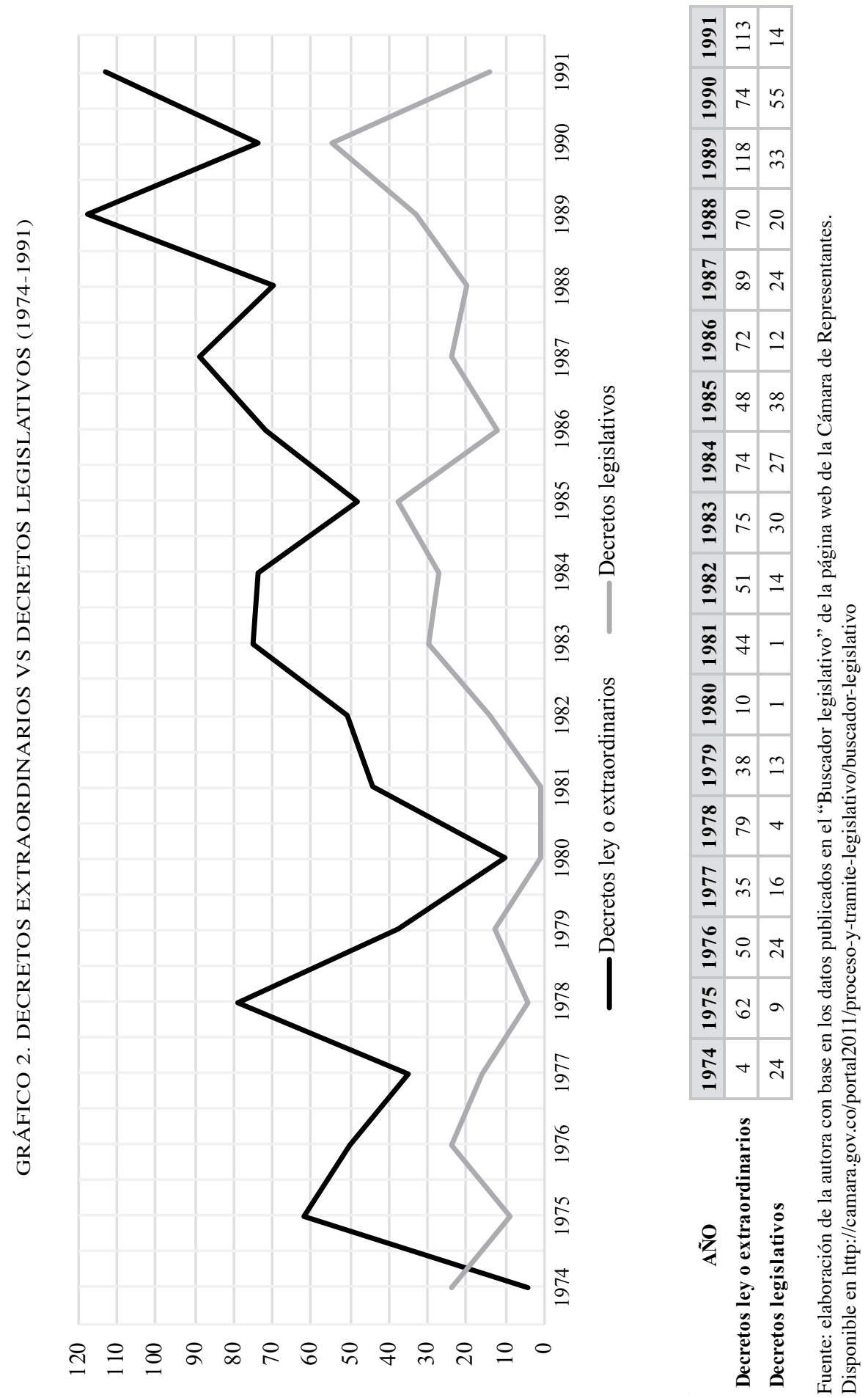
Esta situación plantea la pregunta de cuales fueron los beneficios que recibió el Congreso a cambio de la transferencia de esta facultad. La frecuencia con la que se despojó de la función legislativa ha sido explicada por algunos autores en la pérdida de importancia que significó para él que la reforma de 1968 transfiriera al ejecutivo gran parte de sus facultades económicas y fiscales. Sobre un amplio número de materias de carácter económico, presupuestario, fiscal y monetario "que cubren la casi totalidad de las funciones del Estado moderno", el ejecutivo asumió la iniciativa legislativa exclusiva de aquellos proyectos tendientes a crearlas o reformarlas ${ }^{39}$; de forma que la facultad de presentar proyectos de ley se convirtió en una de las fuentes más importantes del poder presidencial hasta la Constitución de 1991 que le permitía al ejecutivo bloquear al Parlamento. Para Yepes, este Congreso, desprovisto de funciones, no tenía fuerza propia y, por tanto, solo podía comprometer al Gobierno cuando lograba hacerse con el respaldo de la opinión pública. Para justificar esta inactividad se ha recurrido también a explicaciones como "la escasa infraestructura de la institución, que no cuenta con los recursos para agrupar a los expertos ni con la tecnología necesaria para evaluar los proyectos propuestos por el ejecutivo o desarrollar sus propias iniciativas" ${ }^{40}$. Otros autores advierten sobre la comodidad que supone para un Congreso de carácter regional no asumir responsabilidad por las decisiones difíciles que pueden costarle el respaldo de su nicho electoral o incluso, la dificultad de conformar mayorías para aprobar las respectivas leyes ${ }^{41}$.

ral 9). El numeral 10 no se había utilizado para fundamentar tal delegación porque se entendía que hacía referencia exclusivamente a situaciones de anormalidad del orden público y en este sentido, era parte constitutiva del estado de sitio. De las facultades extraordinarias para tiempos de guerra, el congreso y la Corte Suprema derivan entonces unas facultades extraordinarias para tiempos de paz. En este sentido, continúa, "[e]n aquel proceso de transfiguración de las facultades extraordinarias intervinieron, pues, el órgano de la legislación con su praxis tradicional y su cambio de técnica delegativa (del ordinal 9 emigró al 10) y el órgano guardián de integridad de la Constitución. El Poder Constituyente estuvo ausente de ese demiúrgico acontecimiento". Ibíd. 193 y 194. Finalmente, el acto legislativo 1 de 1968 recogió esta doctrina y les atribuyó "fuerza legislativa" a los decretos que expide un presidente tanto en virtud de las "leyes de autorizaciones" (artículo 76 numeral 11), como de "las facultades extraordinarias" (numeral 12) y de los estados de excepción (artículos 121 y 122).

39 Ver YePes ARCILA, H. La reforma constitucional de 1968 y el régimen político colombiano. Manizales: Imprenta Departamental de Caldas, 1974, 159. Estas materias están contempladas en los Ordinales 3, 4, 9 y 22 del artículo 11 del Acto legislativo 1 de 1968, que modifica el artículo 79 de la Constitución de 1886 y parágrafo 2 del artículo 13 del mismo Acto legislativo, que modifica el artículo 79.

40 ARCHER, R. y CHERNICK, M. El presidente frente a las instituciones nacionales. En VÁsQUEZ URRUTIA (ed.). La democracia en blanco y negro: Colombia en los años ochenta. Bogotá: Uniandes, 1989, p. 36.

41 Ver: Carey, J. y Shugart, M. Calling Out the Tanks or Filling Out the Forms? En Carey y Shugart (ed.). Executive Decree Authority. Cambridge: Cambridge University Press, 1998. 
2. EL EJERCICIO DE LA FUNCIÓN LEGISLATIVA A PARTIR DE LA EXPEDICIÓN

DE LA CONSTITUCIÓN DE 1991: SEGUNDO PERIODO (1991- 2014)42

En este periodo, las facultades del ejecutivo de intervenir en el proceso de creación de ley sufren una importante reducción. De un lado, la Constitución especificó aún más los supuestos en que el ejecutivo puede declarar un estado de excepción, limitó los periodos en que puede prorrogar su vigencia y estableció fuertes controles a las facultades que adquiere que incluyen la participación del Congreso y la Corte Constitucional. Dentro de estos límites, se prohibió expresamente que los civiles sean investigados y juzgados por la justicia militar, que se suspendan los derechos humanos y las libertades fundamentales ${ }^{43}$ y que se interrumpa el normal funcionamiento de las ramas del poder público o de los órganos del Estado. Además, las facultades que adquiere el presidente son las estrictamente necesarias para conjurar la situación de anormalidad de forma que, los decretos que expida únicamente pueden referirse a materias que tengan relación directa y específica con la situación que haya dado lugar a su declaratoria y, las medidas adoptadas deben guardar, en todo caso, la proporcionalidad respecto a la gravedad de los hechos.

De otro lado, creó límites respecto a las materias y los términos en los cuales el Congreso puede revestir al presidente de facultades extraordinarias para ejercer la función legislativa. En adelante, la delegación de facultades extraordinarias solo puede hacerse a raíz de una solicitud expresa por parte del gobierno y tiene un límite tanto temporal (para un periodo máximo de seis meses), como material (solo puede referirse a los temas precisos para los que el presidente pide dicha facultad). Además, su aprobación exige la mayoría absoluta de los miembros de ambas cámaras y en ningún caso puede conferirse para expedir códigos, leyes estatutarias u orgánicas, crear servicios administrativos y técnicos de las cámaras o decretar impuestos, materias estas ahora de competencia exclusiva e indelegable del Congreso (artículo 150 núm. $10 \mathrm{cP}$ ).

Así, a diferencia del periodo anterior, a partir de la expedición de la Constitución de 1991 veremos que los códigos ya no son expedidos por el ejecutivo mediante decreto sino por el Congreso a través de una ley ${ }^{44}$. Ejem-

42 El periodo empieza 7 de julio de 1991 (el día después de la promulgación la Constitución de 1991) y termina el 6 de agosto de 2014 (fecha en que termina el mandato del presidente Juan Manuela Santos).

43 Un estudio de lo que estas nuevas exigencias han supuesto para la interpretación de los estados de excepción puede consultarse en: Toвón Toвón, M. Los estados de excepción: imposibilidad de suspensión de los derechos humanos y las libertades fundamentales. Bogotá: Biblioteca de Tesis Doctorales, Grupo Editorial Ibáñez, 2019.

44 Conviene advertir, sin embargo, que a partir de la autorización que hizo el artículo 8 transitorio de la Constitución de 1991, el ejecutivo llevó a cabo una importante operación de "blanqueo" en los términos señalados por García Villegas (2001). En efecto, el presidente adoptó 
plo de ello son el Código Penitenciario y Carcelario (Ley 65 de 1993), el Código Disciplinario Único (Ley 200 de 1995 y Ley 734 de 2002), el Código Penal (Ley 599 de 2000), el Código de Procedimiento Penal (Ley 600 de 2000 y Ley 906 de 2004), el Código de Minas (Ley 685 de 2001), el Código Nacional de Tránsito Terrestre (Ley 769 de 2002), el Código de la Infancia y la Adolescencia (Ley 1098 de 2006), el Código Penal Militar (Ley 1407 de 2010), el Código de Procedimiento Administrativo y de lo Contencioso Administrativo (Ley 1437 de 2011), el Código General del Proceso (Ley 1564 de 2012) y el Código Nacional de Policía y Convivencia (Ley 1801 de 2016), entre otros.

Adicionalmente, a diferencia de la Constitución de 1886, se le otorga al Congreso la facultad de modificar o derogar "en todo tiempo y por iniciativa propia" los decretos extraordinarios expedidos por el ejecutivo (artículo 150 Núm. 10 сP). Teniendo el Parlamento la facultad de revocarlos o modificarlos, la reducción de la mayoría que la Constitución le exige para rechazar el veto del presidente e insistir en la aprobación de un proyecto de ley ${ }^{45}$, también influye sobre la disminución de estos decretos pues, antes de actuar de forma unilateral el presidente calcula, no solo la reacción del Congreso sino además sus posibilidades de impedir, a través del veto de la ley, que este derogue sus medidas ${ }^{46}$. Esto en la medida en que si el Congreso deroga una decisión adoptada mediante decreto, la reputación del presidente puede verse afectada además de quedar impedido en un futuro para recurrir a la estrategia de cambiar el statu quo de forma unilateral.

En este segundo periodo se observa así una gran reducción de la actividad legislativa ejercida por el ejecutivo respecto al periodo anterior. Si entre 1974 y 1991 este sobrepasa la función legislativa ejercida por el parlamento en un $16.9 \%$, en este segundo periodo es el Congreso, quien, con la expedición de 1.732 leyes, consigue triplicar los decretos expedidos por el ejecutivo, que ascienden a 569 (ver gráfico 3). Esta reducción de la actividad legislativa ejercida por el ejecutivo responde, por un lado, a una disminución de las leyes de facultades extraordinarias que le delegan la función legislativa. De

como legislación permanente disposiciones expedidas en ejercicio de las facultades del estado de sitio, tales como el decreto 2252 de 1991 , decreto 2253 de 1991, decreto 2254 de 1991, decreto 2265 de 1991, decreto 2266 de 1991, decreto 2267 de 1991, decreto 2268 de 1991, decreto 2269 de 1991, decreto 2270 de 1991, decreto 2271 de 1991, decreto 2272 de 1991, decreto 2273 de 1991 y decreto 2273 de 1991, entre otros.

45 Bajo la Constitución de 1886, las objeciones del presidente a una ley podían ser rechazadas por el congreso siempre que reuniera una mayoría calificada, es decir, "que fuere adoptado por dos tercios de los votos en una y otra Cámara" (artículo 88). La Constitución de 1991, en cambio, eliminó esta mayoría calificada y estableció un veto "relativamente" débil que puede ser sobrepasado, en cualquier caso, por la mayoría de los miembros de cada cámara (artículo 67).

46 Deering, C. y Maltzman, F. The Politics of Executive Orders: Legislative Constraints on Presidential Power. Political Research Quarterly, Vol. 52, n. ${ }^{\circ} 4,1999$. 
hecho, de las 1.732 leyes aprobadas, 47 revisten al presidente de facultades extraordinarias para legislar y a partir de ellas este expide 311 decretos. Recordemos que en el periodo anterior el Congreso aprueba 86 leyes que otorgan facultades extraordinarias que dan pie a la expedición de 1.106 decretos. En el primer periodo entonces la relación entre leyes que otorgan facultades extraordinarias y decretos extraordinarios es de 1 a 12.86 , mientras que en el segundo periodo esta relación es de 1 a 5.56.

Por otro lado, la reducción de la actividad legislativa ejercida por el ejecutivo obedece a una disminución de los decretos que este expide en el marco de un estado de excepción ${ }^{47}$. Mientras en el primer periodo el presidente expide 349 decretos legislativos, en el segundo estos ascienden a 214. Debe tenerse en cuenta, sin embargo, que los periodos son asimétricos. Mientras en el primero se estudian 17 años, en el segundo quedan incluidos 23 (ver anexo, tabla 2).

Ahora bien, si se comparan los decretos extraordinarios (expedidos a partir de una ley de facultades extraordinarias) con los decretos legislativos (expedidos durante los estados de excepción), se encuentra que en este segundo periodo el presidente también ejerce en su mayor parte la función legislativa a partir de la delegación expresa del parlamento. De los 569 decretos que expide el presidente entre 1991 y 2014, 311 responden a una delegación expresa que hace el Congreso, esto es, un $54.65 \%$, mientras que, con las facultades que le otorgan los estados de excepción, expide 214 , es decir, un $37.60 \%$ del total de decretos (el $7.73 \%$ restante responde a los decretos expedidos a partir de facultades otorgadas directamente por la Constitución). Si bien existe una relación mucho más pareja que en el periodo anterior entre la función legislativa que ejerce el ejecutivo a partir de la delegación de facultades y aquella que ejerce en virtud de un estado de excepción, de nuevo, la altísima actividad legislativa que ejerce el ejecutivo responde a una delegación expresa del Congreso (ver gráfico 4). A pesar de que esta delegación pone en evidencia que el presidente tiene fuertes poderes partidistas que le permiten conseguir tal delegación, es un hecho que el parlamento interviene activamente en la transferencia de sus funciones.

47 Entre 1958 y 2002, García y Uprimny identifican tres fases, “[u]na primera fase, de $<$ emergencia moderada> (1958-1970), en la que uno de cada tres días había estado de sitio; una segunda fase, de <emergencia total> (1970-1991), en la que ocho de cada diez días transcurrían en estado de sitio, y, finalmente, una tercera fase, de <normalización relativa >, a partir de 1991, en la que por el contrario cuatro de cada cinco días eran de normalidad constitucional". Ver ¿Controlando la excepcionalidad permanente en Colombia? Una defensa prudente del control judicial de los estados de excepción, 2005, 23. 


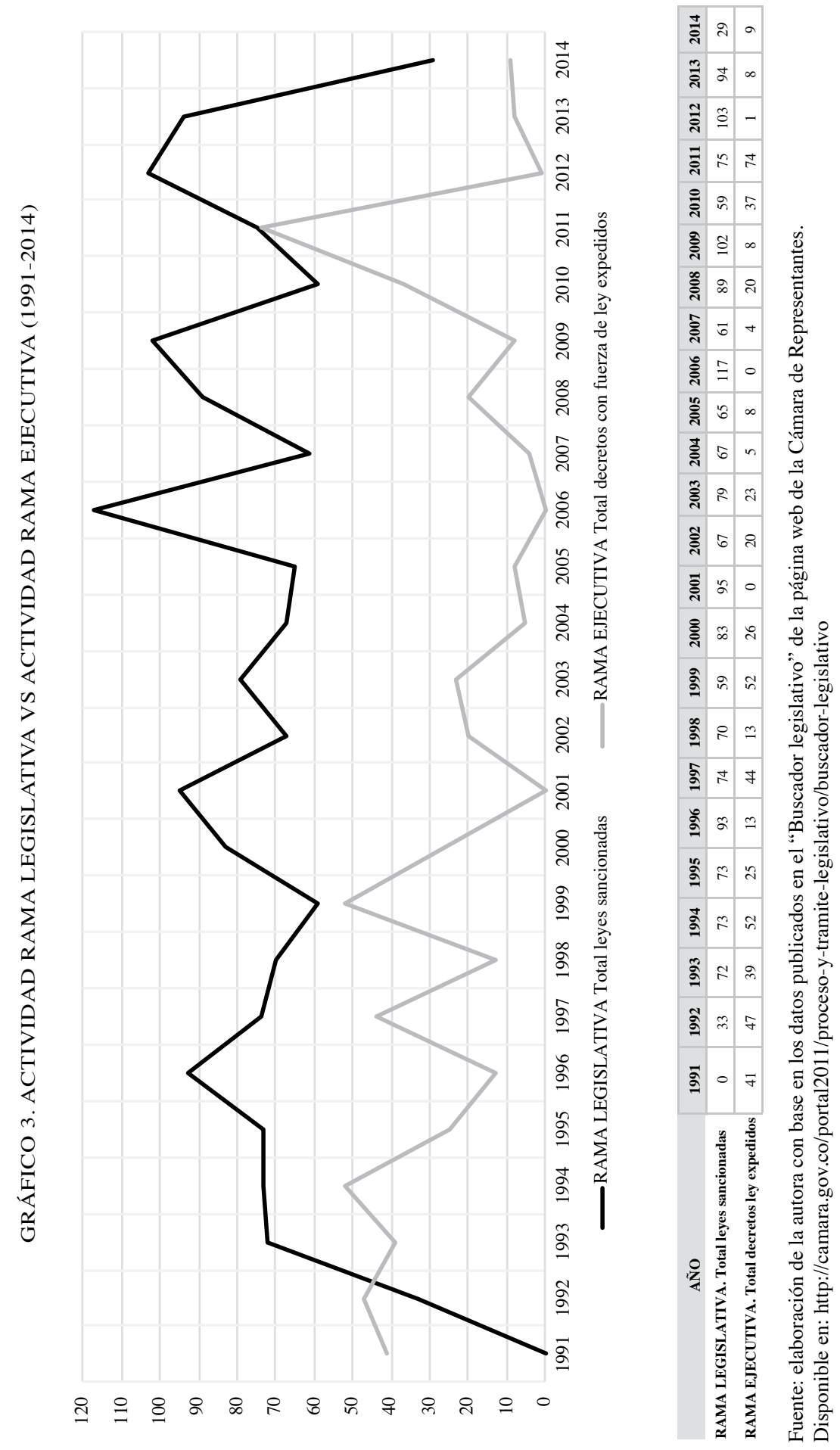


Pasando a un análisis cualitativo de la actividad ejercida por ambas ramas, se constata una gran reducción de la función legislativa ejercida por el presidente. Entre 1974 y 1991, sobre aquellos asuntos que podrían catalogarse como de "mayor importancia" 48 , el Congreso aprobó 472 leyes, mientras que el ejecutivo, sobre los mismos asuntos, había expedido 1.106 decretos, es decir, el ejecutivo había ejercido en más del doble la función legislativa que corresponde al parlamento. Entre 1991 y 2014, en cambio, será el Parlamento quien, con la aprobación de 891 leyes sobre estas materias, casi triplique la actividad del ejecutivo que asciende a 311 decretos. Si en el primer periodo las leyes que aprueba el parlamento respecto de estos asuntos equivalen a un $39,04 \%$ de la totalidad de su actividad, en el segundo representan un $51,44 \%$. Esto demuestra que, de forma progresiva, el Congreso se ha ido apropiando de la función legislativa que le corresponde y ha legislado de forma prioritaria sobre estos temas.

Respecto a los decretos expedidos en virtud de un estado de excepción puede verse que las prácticas políticas intentaron imponerse sobre los cambios normativos pues a pesar de modificarse las reglas de juego en la nueva Carta Política, tanto César Gaviria como Ernesto Samper continuaron con la dinámica de recurrir a ellos como una herramienta para gobernar, dinámica que encontraría un freno en el control ejercido por la Corte Constitucional y que iría reforzándose en el transcurso de los años noventa ${ }^{49}$. En efecto, a diferencia del periodo anterior, en el que la Corte renunció a ejercer un control material sobre la declaración de un estado de excepción, en este una reinterpretación del papel que le corresponde en el entramado institucional le permite ejercer un contrapeso efectivo al ejecutivo ${ }^{50}$. Particularmente

48 Para el periodo anterior se clasificaron las leyes utilizando los cinco criterios utilizados por la Cámara de Representantes en su "buscador legislativo". Para el segundo y tercer periodo además, se suman en la categoría (5) dos nuevos tipos de ley creados por la Constitución de 1991: las leyes orgánicas y las estatutarias. Si bien parece inadecuado dar a las leyes orgánicas y estatutarias el mismo lugar que corresponde a las ordinarias, su reunión en una sola categoría obedece a la necesidad de identificar en qué medida el Congreso ejerce las funciones que le son propias, independientemente del rango que ocupa cada ley dentro del ordenamiento jurídico.

49 El descenso de los periodos de excepcionalidad, afirman García y Uprimny, de un $80 \%$ en los años ochenta a menos de un $20 \%$ a partir de la entrada en vigencia de la Constitución de 1991, no se explica en una reducción en los indicadores de violencia pues, antes que disminuir, esta se ha agravado. La moderación del ejecutivo para recurrir a esta figura responde a los controles que ha ejercido la Corte. Ver ¿Controlando la excepcionalidad permanente en Colombia? Una defensa prudente del control judicial de los estados de excepción, 2005.

50 Pero si el control que ejerce la Corte obliga de forma progresiva al ejecutivo a dejar a un lado los estados de excepción para gobernar con las herramientas que son propias a un estado de "normalidad", este encontrará en las facultades extraordinarias que puede solicitar al congreso una herramienta para continuar ejerciendo la función legislativa y mantener un lugar preponderante dentro del sistema. Un estudio de cómo el hiperpresidencialismo se ha transformado para evadir las reformas constitucionales que recortan las facultades del ejecutivo puede consultarse en: ARANGO ReSTREPO, A.C. Mutaciones del presidencialismo: la transformación del 


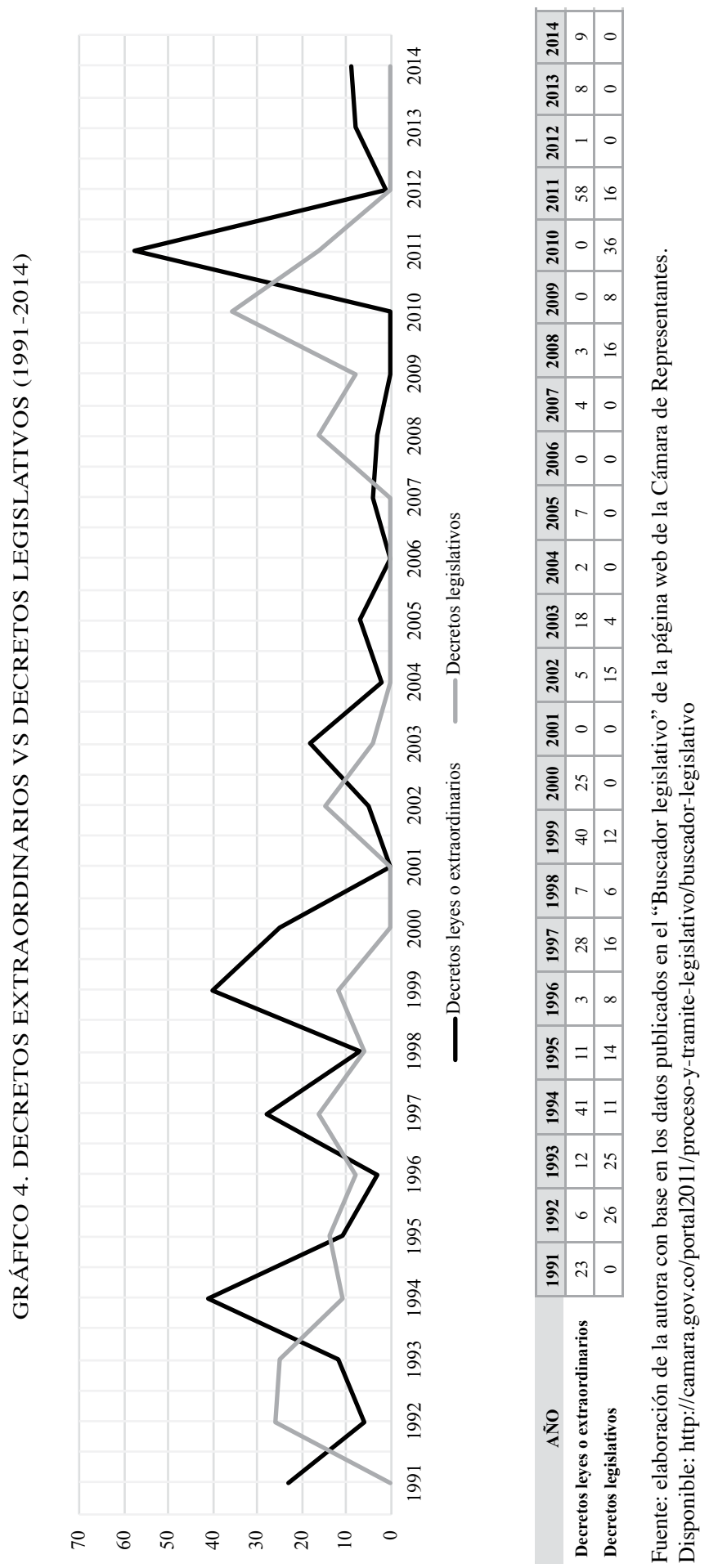


relevante fue su negativa a que se justificara la declaratoria de un estado de excepción en hechos que no fueran coyunturales, transitorios o excepcionales y que, por el contrario, hicieran parte de una perturbación crónica del orden público o económico. Pese a que la Corte tuvo que retroceder en momentos puntuales ante las reiteradas amenazas del ejecutivo y del Congreso de suprimir este tipo de control, el poder presidencial ya no pudo ser ejercido en largos periodos de excepcionalidad ${ }^{51}$.

De los cinco presidentes que componen este periodo, es César Gaviria el presidente al que más le cuesta adaptarse a las nuevas condiciones y el que más recurre a los decretos legislativos a pesar de que, en el conteo de los decretos de este segundo periodo se excluyeron los expedidos en casi dos de los años que componen su mandato por haber sido regulados por la Constitución de 1886. A partir de la declaración de cinco estados de excepción, Gaviria consigue firmar 52 decretos legislativos. Luego Ernesto Samper, que recurre a ellos en tres ocasiones, uno de los cuales es declarado inexequible por la Corte Constitucional, expide 33 decretos legislativos. Por su parte, Andrés Pastrana es el único de este segmento y de la totalidad del periodo de estudio, que no recurre a un estado de conmoción interior y solo declara dos emergencias económicas bajo las cuales expide 16 decretos (ver anexo, tabla 2). Respecto a Álvaro Uribe y Juan Manuel Santos conviene establecer algunas diferencias. Si en el primer mandato de Álvaro Uribe, el presidente declara tan solo un estado de excepción (prorrogado dos veces) y firma 16 decretos - continuando con la dinámica de Andrés Pastrana de no recurrir a ellos como una herramienta para gobernar - en su segundo mandato esta tendencia se revierte y empieza a acercarse de nuevo al uso que se dio a los estados de excepción en los años ochenta pues, a partir de la declaración de

poder presidencial en Colombia (1974-2018). Estudios Constitucionales, Año 17, n. ${ }^{\circ} 2,2019$, 91-120.

51 Este control, sin embargo, no ha sido uniforme y experimenta una serie de cambios que permite a Ariza y Barreto distinguir tres momentos en los años que corresponden a este segundo periodo. El primero, se caracteriza por un "control laxo" en el que la Corte empieza a medir sus fuerzas afirmando su competencia para llevar a cabo un control material sin que efectivamente llegue a ejercerlo. El segundo, se caracteriza por el paso de un control material meramente "retórico" al ejercicio de un contrapeso efectivo a la discrecionalidad del presidente. En el tercero, los autores observan un retroceso - se refieren al momento en que la Corte declara constitucional el segundo intento de Samper de declarar un estado de conmoción interior- que pone nuevamente de manifiesto la debilidad de la Corte para llevar a cabo un control material. No obstante, advierten, este tipo de decisión estuvo condicionada por un contexto en el que el ejecutivo amenazaba con recortar las facultades de la Corte y esta se afanaba por mantener una posición fuerte frente a la opinión pública. Ver La Corte Constitucional frente a la excepcionalidad: diez años de control material laxo y discursivo. Derecho Constitucional. Perspectivas críticas. Bogotá: Observatorio de Justicia Constitucional-Universidad de los Andes, 2001, 158 у 159 . 
seis estados de excepción, el presidente expide 33 decretos legislativos ${ }^{52}$. Una particularidad importante de este segundo mandato de Álvaro Uribe es que, a diferencia del resto del periodo de estudio, es el único segmento en el que no puede afirmarse que el ejercicio de la función legislativa por parte del presidente responda en mayor proporción a una delegación que hace el parlamento de sus funciones pues esta fue ejercida de forma preponderante a partir de las facultades que le otorgaron los estados de excepción. Por su parte, Juan Manuel Santos continúa acentuando la tendencia de recurrir los estados de excepción y a partir de dos declaratorias, expide un total de 36 decretos.

En relación con los decretos expedidos a partir de una ley de facultades extraordinarias, los presidentes de este periodo recurren a ellos en una proporción más o menos equivalente (César Gaviria expide 78 decretos extraordinarios; Ernesto Samper, 50; Andrés Pastrana, 73 y Juan Manuel Santos, 76). En el caso de Álvaro Uribe, sin embargo, este tipo de decretos se reduce casi a la mitad durante su primer mandato y a menos de una quinta parte en el segundo. Álvaro Uribe es así el presidente en quien delega menos el Congreso la función legislativa ${ }^{53}$. La bajísima utilización de las facultades extraordinarias a partir de 2004 puede explicarse en que para este año el presidente ha conseguido formar una coalición "aplastante" que le permite obtener la aprobación de su agenda de gobierno sin que sea necesario impulsarlas de forma unilateral mediante decreto. En el primer periodo de

52 Vanegas, por ejemplo, identifica dos etapas. Una primera que puede situarse a finales de la década de los noventa y casi la primera década del siglo XXI (cogería parte del mandato de Pastrana y el primer mandato de Álvaro Uribe), que se caracteriza "por cierta madurez política de los gobiernos de turno" que supuso afrontar los problemas de orden público a través de las herramientas propias a un estado de normalidad, en lugar de recurrir a los estados de excepción. La segunda etapa en cambio, "se caracteriza por recurrir de nuevo de manera inercial a la figura de los poderes de excepción, desde el 2008 hasta principios del 2011. En este espacio de tiempo de casi tres años se han declarado en siete ocasiones los estados de excepción: seis emergencias y una conmoción interior. Esta tendencia facilista pareciera sugerir un retroceso en el uso de los estados de excepción como garantía última de la Constitución". Ver Vanegas Gi, P. La Constitución colombiana y los estados de excepción: veinte años después. Revista Derecho del Estado, n. . 27, 2011, 286.

53 A través de la solicitud de facultades extraordinarias al congreso, el presidente Álvaro Uribe se proponía cumplir con su promesa de campaña de reformar la Constitución y simplificar el Estado para acabar con la corrupción y la politiquería. Ver Medellín torres, P. El presidente sitiado: ingobernabilidad y erosión del poder presidencial en Colombia. Bogotá: Planeta, 2006, 197 y 198. A través de estas facultades extraordinarias el presidente pudo suprimir, fusionar y transformar los ministerios y otras entidades del Estado. Nueve años más tarde, en el 2011, Juan Manuel Santos pidió al congreso facultades extraordinarias para escindir nuevamente estos ministerios y modificar la estructura administrativa del Estado. Además de las reformas al ejecutivo, estas facultades, como bien señala Duque Daza, se han usado "para adelantar negociaciones con actores armados ilegales. Uribe las recibió a manera de prórroga de la Ley 418 de 1997 (de facultades al presidente Samper), que a su vez habían sido concedidas a Pastrana (Ley 548 de 1999). Así surgió la Ley 782 de 2002, que serviría de marco para las negociaciones de Uribe con los paramilitares". Ver: Ver: DuQue DAZA, J. Facultades extraordinarias para la paz: ¿presidencialismo excesivo o delegación legítima de poderes?, Razón Pública, 2015. 
Juan Manuel Santos puede evidenciarse el mismo fenómeno a partir del año 2012. En efecto, el $76.3 \%$ de los decretos extraordinarios son expedidos durante los dos primeros años de su mandato mientras el presidente lograba construir una amplia mayoría en el parlamento que le permitiera obtener la aprobación de su agenda a través del procedimiento legislativo ordinario. Una vez se hace con una mayoría "aplastante" los decretos extraordinarios se reducen de forma notable.

En los últimos años de este periodo entonces, el Congreso delega menos y el presidente, a su vez, ejerce menos la función legislativa. La disminución de su actuación unilateral coincide con el fortalecimiento de sus poderes partidistas. En esta medida, la aprobación de su agenda se consigue ya no desde fuera del Parlamento, esto es, a partir de decretos del ejecutivo, sino desde dentro gracias a la construcción de fuertes coaliciones que le permiten pasar sus proyectos de ley. La reducción de facultades legislativas que continúa en este periodo y que fue instaurada en la Constitución de 1991, se suple así a través de fuertes poderes partidistas ${ }^{54}$.

El hecho de preferir recurrir a la legislación que al decreto ha sido explicado por la doctrina en la tesis según la cual, teniendo la ley un mayor grado de estabilidad que los decretos, siempre que un presidente tenga apoyo en el Congreso preferirá implementar su agenda a través suyo en lugar de hacerlo de forma unilatera ${ }^{55}$. En este sentido, advierte Amorim, solo los presidentes que tienen una porción considerable de sillas en el parlamento y que están ideológicamente en el centro, tienen más probabilidades de ejecutar su programa de gobierno recurriendo a una estrategia basada en la legislación ${ }^{56}$. Si los presidentes no cumplen con estas condiciones o tienen amplias facultades para expedir decretos y vetar la ley, buscarán conseguir sus metas recurriendo a sus prerrogativas unilaterales. En los casos intermedios, en los que la mayoría no es muy fuerte pero es manejable, el presidente podrá negociar la aprobación de su agenda a cambio de prebendas, puestos en el gabinete, concesiones en la definición de sus políticas o de la agenda legislativa ${ }^{57}$.

54 Arango Restrepo, A.C. Mutaciones del presidencialismo: la transformación del poder presidencial en Colombia (1974-2018). Estudios Constitucionales, Año 17, n. ${ }^{\circ}$ 2, 2019, 106 y 107.

55 Cox, G. y Morgenstern, S. Latin America's Reactive Assemblies and Proactive Presidents. Comparative Politics, Vol. 33, n. ${ }^{\circ} 2,2001,175-178$.

56 Amorim Neto, O. The Presidential Calculus: Executive Policy Making and Cabinet Formation in the Americas. Comparative Political Studies, Vol. 39, n. . 4, 2006, 436-437.

57 En el primer caso, esto es, cuando el presidente encuentra que puede comprar una mayoría en el congreso a partir de prebendas, esta preferirá que el presidente tome el control de la política nacional y le otorgará la facultad de implementar su agenda, en su mayor parte, a través de decretos. En el segundo caso, en cambio, cuando dicha mayoría exige puestos en el gabinete, concesiones en la definición de sus políticas o de la agenda legislativa, el congreso participa activamente del proceso político y la agenda del presidente se aprobará a través suyo. 
Por último, conviene advertir que durante este periodo tiene lugar una nueva modalidad de delegación de facultades extraordinarias. A partir de 2003, se utilizaron las reformas constitucionales para otorgar estas facultades al presidente y permitirle ejercer la función legislativa respecto de materias que están expresamente prohibidas en la Constitución. La Constitución de 1991 prohibió al Congreso transferir al ejecutivo la facultad de expedir códigos, leyes estatutarias, leyes orgánicas, crear los servicios administrativos y técnicos de las cámaras o decretar impuestos. El incumplimiento de este requisito acarrea una declaración de inconstitucionalidad de la ley y de los decretos que a partir de ella se expidan, en caso de que se demande su exequibilidad ante la Corte Constitucional. Para saltarse esta prohibición y el control de la Corte, el Congreso encontró en las reformas constitucionales el mecanismo adecuado para delegar en el ejecutivo la regulación de materias sobre las cuales tiene competencia exclusiva. Sobre este punto advierten Quinche y Urrego, el constituyente secundario revistió al presidente de facultades extraordinarias, en parágrafos transitorios, para regular materias con reserva de ley estatutaria u orgánica, en caso de que el Congreso no lo hiciera en los plazos previstos por dichas reformas ${ }^{58}$. Esta delegación se contempló en el Acto Legislativo 3 de 2002, el Acto Legislativo 2 de 2003, las preguntas 6 y 7 de la Ley 796 de 2003 (que convocaba a un referendo constitucional), el Acto Legislativo 2 de 2005, el Acto Legislativo 4 de 2007 y el Acto Legislativo 1 de 2013.

\section{CONCLUSIÓN}

En Colombia, en el periodo comprendido entre 1974 y 2014 el presidente ha ejercido en una medida importante la función legislativa ${ }^{59}$. Esta estrategia le ha permitido cambiar el statu quo de forma unilateral y en la dirección que a él le ha convenido. No obstante, los datos recogidos permiten corroborar la tesis de que cuando se trata de recurrir a los mecanismos "excepcionales"

Ver Cox, G. y Morgenstern, S. Latin America's Reactive Assemblies and Proactive Presidents. Comparative Politics, Vol. 33, n. ${ }^{\circ} 2,2001,173$

58 Quinche Ramírez, M. y UrRego Ortiz, F. Los decretos presidenciales en el sistema normativo. Bogotá: Ed. Doctrina y Ley Ltda., 2011, pp. 297-312.

59 No solo los presidentes latinoamericanos tienen la tendencia a expandir sus poderes. Autores como Mayer llaman la atención sobre la expansión gradual que han sufrido por poderes del presidente norteamericano. Con el paso del tiempo, advierte, los presidentes han aprovechado los vacíos constitucionales y legales para asumir el control de espacios significativos de la política gubernamental, confiando en la incapacidad del congreso de reaccionar de forma oportuna. De hecho, el presidente es quien está mejor posicionado para expandir los límites institucionales y el resultado inevitable parece ser una constante concentración de poder dentro de la rama ejecutiva. Si a esta concentración de poder se suma un congreso ineficiente y un poder judicial condescendiente, las posibilidades de que el presidente abuse de su poder aumentan. Ver MAYER, K. With The Stroke of a Pen: Executive Orders and Presidential Power. Princeton, New Jersey: Princeton University Press, 2001, p. 220. 
en lugar de los "ordinarios" para conseguir la aprobación de su agenda, el presidente ha preferido, en una proporción sustancialmente mayor, solicitar al Congreso la delegación de la función legislativa que ejercerla con las facultades que le otorgan los estados de excepción. Incluso en el periodo en que el presidente pudo recurrir a estos últimos casi sin restricciones, esto es, entre 1974 y 1991 , los decretos legislativos representan apenas un $24.14 \%$ de la totalidad de decretos con fuerza de ley expedidos por el presidente. Si bien en futuras investigaciones vale la pena profundizar en las razones que llevan al ejecutivo a elegir uno u otro tipo de decreto, la utilización preponderante de los decretos extraordinarios podría explicarse, de forma preliminar, en la estabilidad que tienen las medidas adoptadas por estos y los controles que sobre ellos se ejercen. En efecto, mientras que los decretos extraordinarios tienen una vigencia indefinida y un control posterior por vía de acción que corresponde ejercer a la Corte Constitucional, los decretos legislativos pierden su vigencia, por regla general, inmediatamente se levanta el estado de excepción y son objeto de un control jurídico automático ejercido por la Corte Constitucional y uno de carácter político adelantado por el Congreso.

Por otro lado, la reducción tanto de los decretos legislativos como de los decretos extraordinarios a partir de la expedición de la Constitución de 1991, pone en evidencia que los cambios institucionales han jugado un papel importante sobre el ejercicio de la función legislativa por parte del presidente. En el segundo periodo (1991-2014), la función legislativa que lleva a cabo el Congreso es tres veces mayor a la ejercida por el ejecutivo. Este hecho puede explicarse en una disminución de las leyes de facultades extraordinarias y de los casos en los que el presidente ha recurrido a la declaración de un estado de excepción y que puede atribuirse a los límites impuestos por el constituyente de 1991. Pero, aun cuando se reducen los decretos con fuerza de ley en el segundo periodo, los decretos extraordinarios siguen representando un $62.39 \%$ del total de decretos expedidos, lo cual significa que el ejercicio de la función legislativa obedece, principalmente, a la delegación expresa que ha hecho el Congreso de las funciones que le corresponden y no a usurpación por parte del ejecutivo.

Otro hallazgo importante es que a pesar de que los decretos con fuerza de ley se reducen a partir de la expedición de la Constitución de 1991, en los años en los que el presidente consigue el apoyo de mayorías "aplastantes" en el Congreso se constata una reducción todavía mayor de estos decretos (tanto de los legislativos como de los extraordinarios). Esto corrobora la tesis de la doctrina de que siendo más estable la ley que el decreto, siempre que el presidente tenga un fuerte respaldo va a preferir obtener la aprobación de su agenda a través del procedimiento legislativo ordinario que recurrir a su actuación unilateral.

Respecto a la relación entre ambos tipos de decreto, pudo evidenciarse a lo largo del periodo que el aumento de la frecuencia con que el presidente 
recurre a un estado de excepción se corresponde con una disminución de la delegación de facultades extraordinarias que recibe del Congreso y en este sentido, los años en los que aumentan los decretos legislativos, disminuyen los extraordinarios y viceversa. Aunque debe ahondarse en el estudio de esta relación, puede decirse que esto reafirma la tesis de Pereira, Power y Rennó en la medida en que las variaciones coinciden con la conformación del Parlamento y el apoyo que un presidente en concreto consigue en él. De forma que, el presidente tiende a hacer un mayor uso de las facultades extraordinarias cuando se enfrenta a una asamblea que coopera y le delega la función legislativa. Por el contrario, el presidente ha utilizado los estados de excepción para aprobar su agenda sin necesidad de conseguir el apoyo del Congreso, es decir, pasando por encima suyo, cuando este le hace oposición o simplemente, cuando no tiene suficientes poderes partidistas para conseguir tal delegación ${ }^{60}$.

Vale la pena resaltar que en la última parte del segundo periodo tiene lugar una modalidad alarmante de delegación de la función legislativa que ya no supone la aprobación de leyes de facultades extraordinarias. La estrategia del Congreso de recurrir a reformas constitucionales para delegar en el ejecutivo la facultad de legislar sobre materias que el constituyente le asignó a él de forma exclusiva, evidencia su interés de saltarse la prohibición de la Carta y superar el control que está llamado a ejercer sobre las leyes de facultades extraordinarias la Corte Constitucional. Esta nueva práctica podría llegar a revertir la tendencia a la baja que pudo evidenciarse respecto de los decretos con fuerza de ley a partir de la expedición de la Constitución de 1991 y la consagración de límites expresos al ejercicio de la función legislativa por parte del presidente.

Para concluir, estudiar la frecuencia con la que se expiden decretos con fuerza de ley en un periodo determinado es importante porque indica la medida en que el ejecutivo ejerce la función legislativa, pero sobre todo porque la expedición de estos decretos encierra un problema político, el problema de la representación, y nos muestra quién ejerce dicha función de forma dominante en el caso colombiano. Los datos expuestos ameritan replantear el debate acerca de la sustitución que puede hacer el ejecutivo del órgano representativo en los sistemas presidenciales a partir de otras figuras - como los decretos extraordinarios - que, en principio, no parecen tan invasivas como los estados de emergencia y a los que no se ha prestado suficiente atención. Así las cosas, los peligros que encierra la actuación unilateral del ejecutivo para una democracia deben abordarse no solo como una usurpación de la función legislativa por parte del ejecutivo, sino también como una decisión

60 Pereira, C., Power, T. y Rennó, L. Under What Conditions Do Presidents Resort to Decree Power? Theory and Evidence from the Brazilian Case. The Journal of Politics, Vol. 67, n. ${ }^{\circ} 1,2005,194-195$. 
de las mayorías en el Congreso de delegar dicha función que exige indagar cuáles son las razones que la llevan a hacerlo y cómo puede revertirse esta tendencia.

\section{REFERENCIAS}

Amorim Neto, O. The Presidential Calculus: Executive Policy Making and Cabinet Formation in the Americas. Comparative Political Studies, Vol. 39, n. ${ }^{\circ} 4,2006,415-440$.

Arango Restrepo, A.C. Mutaciones del presidencialismo: la transformación del poder presidencial en Colombia (1974-2018). Estudios Constitucionales, Año 17, n. 2 2, 2019, 91-120.

ArCher, R. y CHERnick, M. El presidente frente a las instituciones nacionales. En VÁsQuez Urrutia (ed.). La democracia en blanco y negro: Colombia en los años ochenta. Bogotá: Uniandes, 1989, 31-79.

Archer, R. y Shugart, M. The Unrealized Potential of Presidential Dominance in Colombia. En Mainwaring y Shugart (ed.). Presidentialism and Democracy in Latin America. Cambridge: Cambridge University Press, 1997, 110-159.

Ariza, L. y Barreto A. La Corte Constitucional frente a la excepcionalidad: diez años de control material laxo y discursivo. En Derecho Constitucional. Perspectivas críticas. Bogotá: Observatorio de Justicia Constitucional-Universidad de los Andes, 2001,137-171.

Barreto, A. La generación del estado de sitio: el juicio a la anormalidad institucional colombiana en la Asamblea Nacional Constituyente de 1991. Precedente. Revista Jurídica, Vol. 1, 9-48.

Carey, J. y Shugart, M. Calling out the Tanks or Filling Out the Forms? En Carey y Shugart (ed.). Executive Decree Authority. Cambridge: Cambridge University Press, 1998, 1-32.

Cox, G. y Morgenstern, S. Latin America's Reactive Assemblies and Proactive Presidents. Comparative Politics, Vol. 33, n. ${ }^{\circ}$ 2, 2001, 171-189.

Deering, C. y Maltzman, F. The Politics of Executive Orders: Legislative Constraints on Presidential Power. Political Research Quarterly, Vol. 52, n. ${ }^{\circ}$ 4, 1999, 767-783.

Duque DazA, J. "Facultades extraordinarias para la paz: ¿presidencialismo excesivo o delegación legítima de poderes?", 2015, Disponible en: http://www.razonpublica.com/ index.php/conflicto-drogas-y-paz-temas-30/8841-facultades-extraordinarias-para-lapaz-\% C2\%BFpresidencialismo-excesivo-o-delegaci\%C3\%B3n-leg\%C3\% ADtima-depoderes.html (consultado el 30 noviembre de 2018).

Ferejohn, J. y Pasquino, P. The Law of the Exception: A Typology of Emergency Powers. International Journal of Constitutional Law, Vol. 2, n. . 2, 2004, 210-239.

Gallón Giraldo, G. Quince años de estado de sitio en Colombia, 1958-1978. Bogotá: Editorial América Latina, 1979.

García Villegas, M. Constitucionalismo perverso. Normalidad y anormalidad constitucional en Colombia (1957-1997). En Santos y García Villegas (dirs.). El caleidoscopio 
de las justicias en Colombia. Bogotá: Uniandes-Siglo del Hombre-Colciencias-Ces, Tomo I, 2001, 317-370.

García Villegas, M. y Uprimny, R. ¿Controlando la excepcionalidad permanente en Colombia? Una defensa prudente del control judicial de los estados de excepción, 2005, Disponible en http://www.dejusticia.org/files/r2_actividades_recursos/fi_name_recurso.198.pdf (consultado el 20 de abril de 2018).

Hartlyn, J. Presidentialism and Colombian Politics. En Linz y Valenzuela (edit.) The Failure of Presidential Democracy: The Case of Latin America, Vol. 2, Baltimore: The Johns Hopkins University Press, 1994, 220-253.

Howell, W. Unilateral Powers: A Brief Overview. Presidential Studies Quarterly, Vol. $35,{ }^{\circ}{ }^{\circ} 3,2005,417-439$.

Mayer, K. Executive Orders and Presidential Power. The Journal of Politics, Vol. 61, n. ${ }^{\circ}$ 2, 1999, 445-466.

Mayer, K. With The Stroke of a Pen: Executive Orders and Presidential Power. Princeton, New Jersey: Princeton University Press, 2001.

Medellín Torres, P. El presidente sitiado: ingobernabilidad y erosión del poder presidencial en Colombia. Bogotá: Planeta, 2006.

Moe, T. y Howell, W. The Presidential Power of Unilateral Action. The Journal of Law, Economics, and Organization, Vol. 15, n. ${ }^{\circ}$ 1, 1999, 132-179.

Negretto, G. El constitucionalismo puesto a prueba: decretos legislativos y emergencia económica en América Latina. Isonomía, n. ${ }^{\circ}$ 14, 2001, 79-106.

Negretto, G. ¿Gobierna solo el presidente? Poderes de decreto y diseño institucional en Brasil y Argentina. Desarrollo Económico, Vol. 42, n. ${ }^{\circ}$ 167, 2002, 377-404.

Pereira, C., Power, T. y Rennó, L. Under What Conditions Do Presidents Resort to Decree Power? Theory and Evidence from the Brazilian Case. The Journal of Politics, Vol. 67, n. ${ }^{\circ} 1,2005,178-200$.

Quinche Ramírez, M. y UrRego Ortiz, F. Los decretos presidenciales en el sistema normativo. Bogotá: Ed. Doctrina y Ley Ltda., 2011.

Restrepo Piedrahita, C. Las facultades extraordinarias. Bogotá: Publicaciones Universidad Externado de Colombia, 1973.

Shugart, M. y Mainwaring, S. Presidentialism and Democracy in Latin America: Rethinking the Terms of the Debate. En Mainwaring y Shugart (edit.). Presidentialism and Democracy in Latin America. Cambridge: Cambridge University Press, 1997, 12-54.

Shugart, M. y Haggard, S. Institutions and Public Policy in Presidential Systems. En HaGgard (edit.) Presidents, Parliaments, and Policy. Cambridge: Cambridge University Press, 2001, 64-102.

Товón Товón, M. Los estados de excepción: imposibilidad de suspensión de los derechos humanos y las libertades fundamentales. Bogotá: Biblioteca de tesis doctorales, Grupo Editorial Ibáñez, 2019. 
UPRIMnY YePes, R. Estado de sitio y tratados internacionales en Colombia: una crítica a la jurisprudencia constitucional de la Corte. En Gallón Giraldo (comp.) Guerra y constituyente. Bogotá: Comisión Andina de Juristas Seccional Colombiana, 1991, 90-101.

VANegas Gil, P. La Constitución colombiana y los estados de excepción: veinte años después. Revista Derecho del Estado, n. ${ }^{\circ}$ 27, 2011, 261-290.

Yepes Arcila, H. La reforma constitucional de 1968 y el régimen político colombiano. Manizales: Imprenta Departamental de Caldas, 1974. 


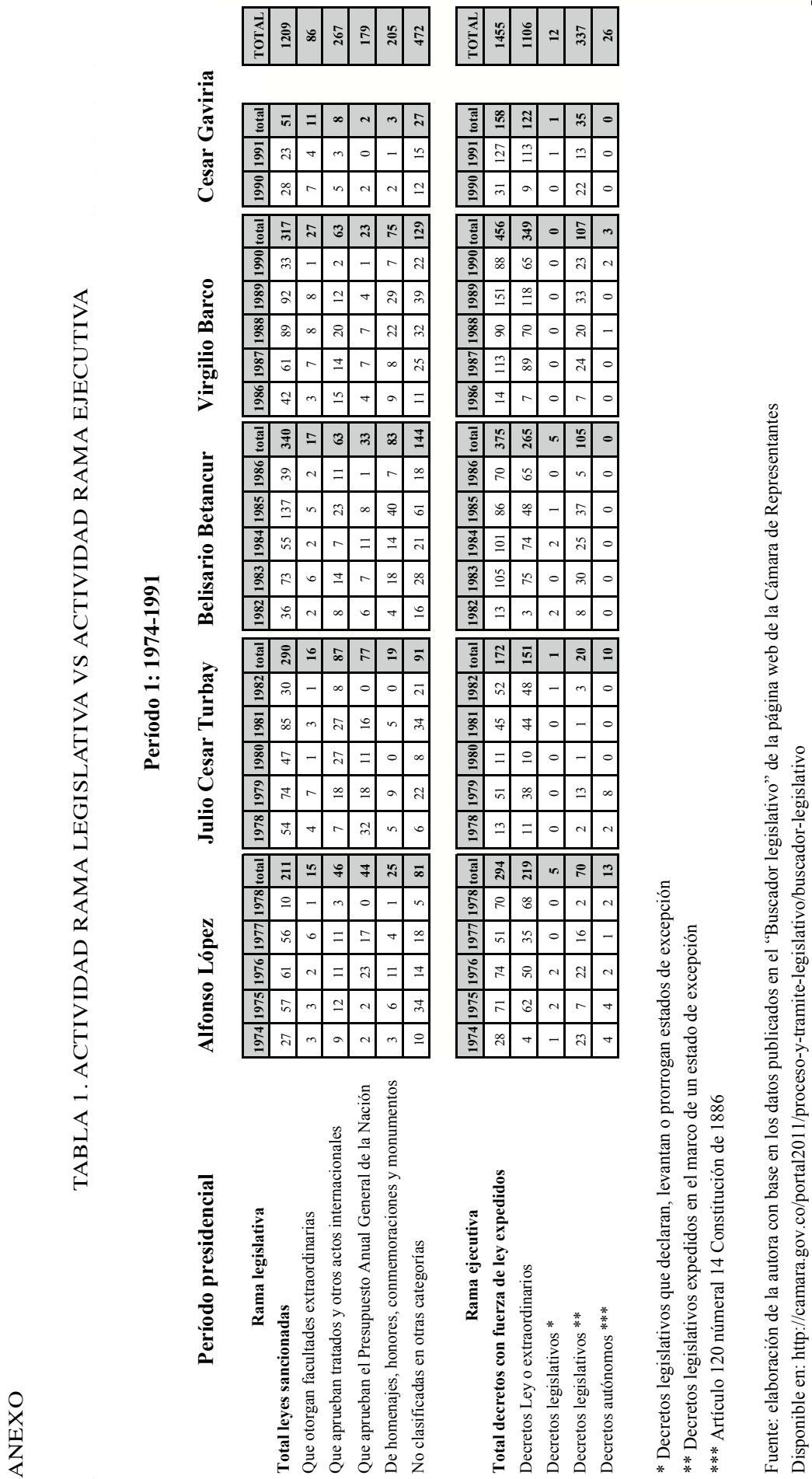




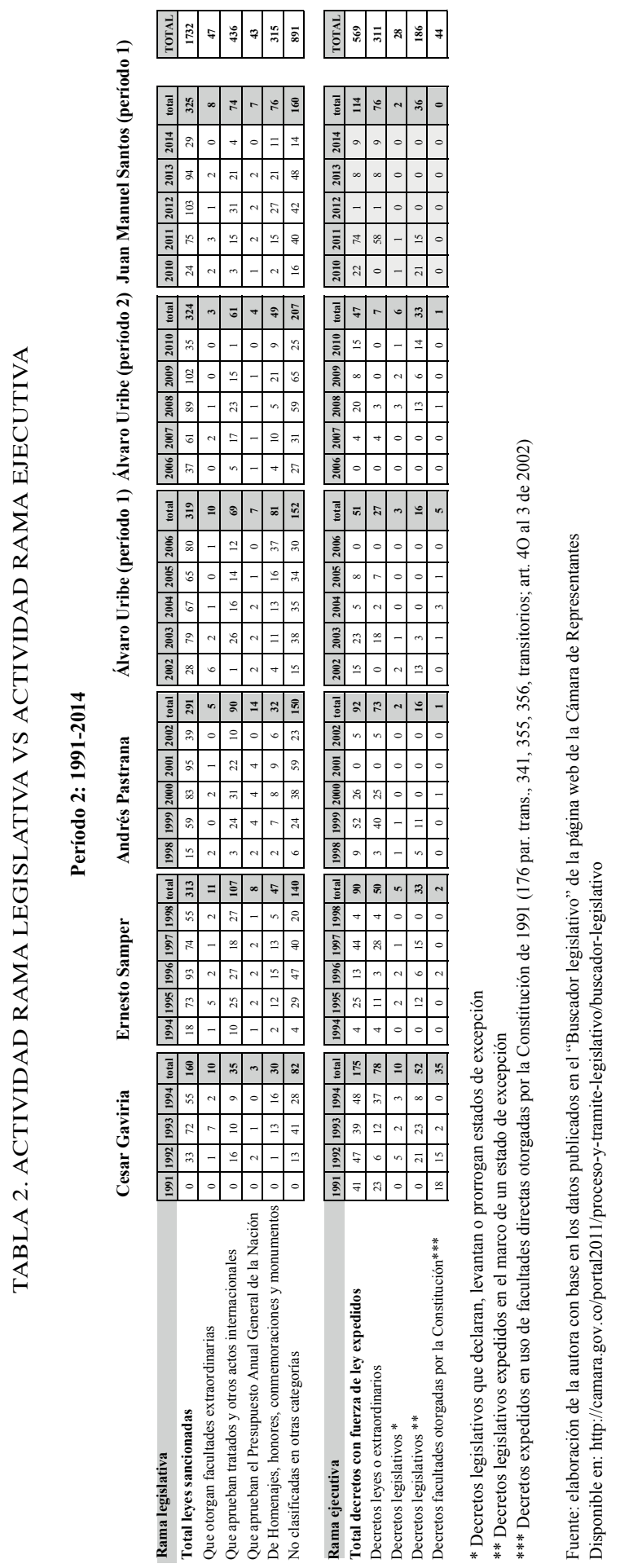

